Digital Comprehensive Summaries of Uppsala Dissertations from the Faculty of Medicine 1135

\title{
On Surgery for Lumbar Spinal Stenosis
}

PETER FÖRSTH

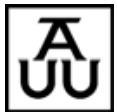

ACTA UNIVERSITATIS UPSALIENSIS UPPSALA 2015
ISSN 1651-6206

ISBN 978-91-554-9340-0

urn:nbn:se:uu:diva-262525 
Dissertation presented at Uppsala University to be publicly examined in Eva Netzeliussalen, Blåsenhus, von Kraemers Allé 1A, Uppsala, Friday, 6 November 2015 at 13:00 for the degree of Doctor of Philosophy (Faculty of Medicine). The examination will be conducted in Swedish. Faculty examiner: Professor Helena Brisby (Department of orthopedics, Institute of Clinical Sciences, Sahlgrenska Academy, University of Gothenburg).

\author{
Abstract \\ Försth, P. 2015. On Surgery for Lumbar Spinal Stenosis. Digital Comprehensive Summaries \\ of Uppsala Dissertations from the Faculty of Medicine 1135. 66 pp. Uppsala: Acta \\ Universitatis Upsaliensis. ISBN 978-91-554-9340-0.
}

The incidence of lumbar spinal stenosis (LSS) is steadily rising, mostly because of a noticeably older age structure. In Sweden, LSS surgery has increased continuously over the years and is presently the most common argument to undergo spine surgery. The purpose of the surgery is to decompress the neural elements in the stenotic spinal canal. To avoid instability, there has been a tradition to do the decompression with a complementary fusion, especially if degenerative spondylolisthesis is present preoperatively.

The overall aims of this thesis were to evaluate which method of surgery that generally can be considered to give sufficiently good clinical results with least cost to society and risk of complications and to determine whether there is a difference in outcome between smokers and non-smokers.

The Swespine Register was used to collect data on clinical outcome after LSS surgery. In two of the studies, large cohorts were observed prospectively with follow-up after 2 years. Data were analysed in a multivariate model and logistic regression. In a randomised controlled trial (RCT, the Swedish Spinal Stenosis Study), 233 patients were randomised to either decompression with fusion or decompression alone and then followed for 2 years. The consequence of preoperative degenerative spondylolisthesis on the results was analysed and a health economic evaluation performed. The three-dimensional CT technique was used in a radiologic biomechanical pilot study to evaluate the stabilising role of the segmental midline structures in LSS with preoperative degenerative spondylolisthesis by comparing laminectomy with bilateral laminotomies.

Smokers, in comparison with non-smokers, showed less improvement after surgery for LSS. Decompression with fusion did not lead to better results compared with decompression alone, no matter if degenerative spondylolisthesis was present preoperatively or not; nor was decompression with fusion found to be more cost-effective than decomression alone. The instability caused by a decompression proved to be minimal and removal of the midline structures by laminectomy did not result in increased instability compared with the preservation of these structures by bilateral laminotomies.

In LSS surgery, decompression without fusion should generally be the treatment of choice, regardless of whether preoperative degenerative spondylolisthesis is present or not. Special efforts should be targeted towards smoking cessation prior to surgery.

Keywords: spinal stenosis, decompression, fusion, degenerative spondylolisthesis

Peter Försth, Department of Surgical Sciences, Akademiska sjukhuset, Uppsala University, SE-75185 Uppsala, Sweden.

(C) Peter Försth 2015

ISSN 1651-6206

ISBN 978-91-554-9340-0

urn:nbn:se:uu:diva-262525 (http://urn.kb.se/resolve?urn=urn:nbn:se:uu:diva-262525) 
To Agnes, Saga and Lisa 



\section{List of Papers}

This thesis is based on the following papers, which are referred to in the text by their Roman numerals.

I Sandén, B., Försth, P., Michaëlsson, K. (2011) Smokers show less improvement than nonsmokers two years after surgery for lumbar spinal stenosis: a study of 4555 patients from the Swedish spine register. Spine 2011 Jun;36(13):1059-64.

II Försth, P., Michaëlsson, K., Sandén, B. (2013) Does fusion improve the outcome after decompressive surgery for lumbar spinal stenosis?: a two-year follow-up study involving 5390 patients. Bone Joint J. $2013 \mathrm{Jul} ; 95-B(7): 960-5$.

III Försth, P., Ólafsson, G., Carlsson, T., Frost, A., Borgström, F., Fritzell, P., Öhagen, P., Michaëlsson, K., Sandén, B. (2015) Efficacy of fusion surgery for lumbar spinal stenosis. Clinical and economic results from a 2-year multicenter randomized controlled trial in Sweden. Submitted.

IV Försth, P., Svedmark, P., Noz M.E., Maguire Jr, G.Q., Zeleznik M.P., Sandén, B. 3D Motion analysis using provocation computed tomography in lumbar spinal stenosis with degenerative spondylolisthesis before and after decompressive surgery: A randomised comparative pilot study of laminectomy versus bilateral laminotomy. Manuscript.

Reprints were made with permission from the respective publishers. 



\section{Contents}

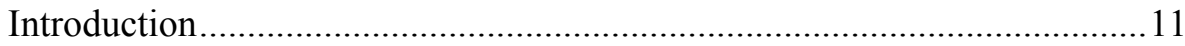

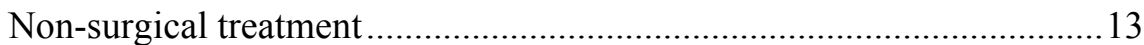

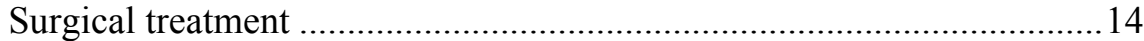

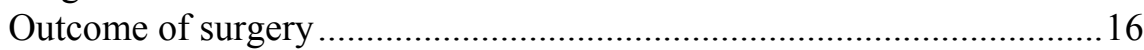

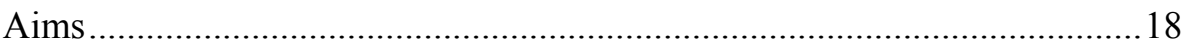

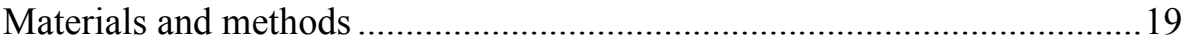

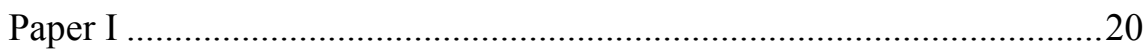

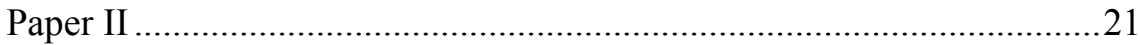

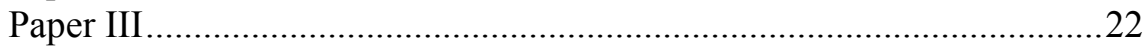

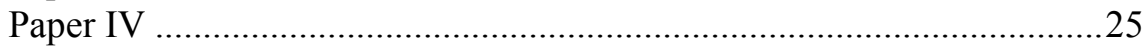

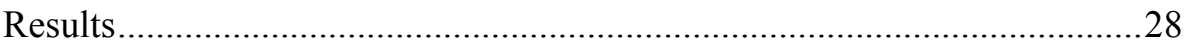

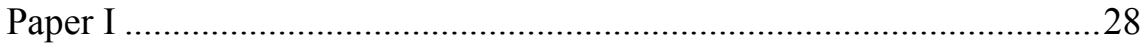

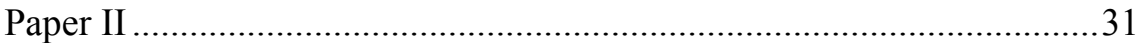

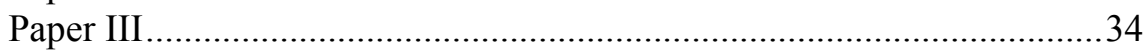

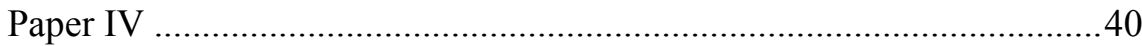

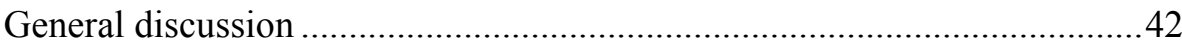

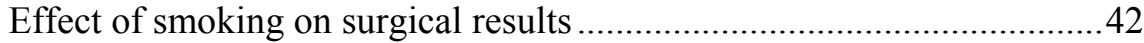

To fuse or not to fuse in decompressive surgery ....................................43

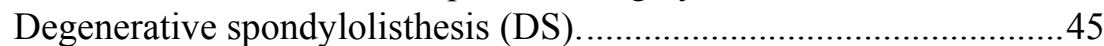

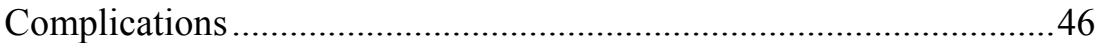

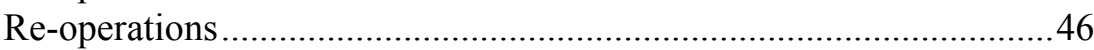

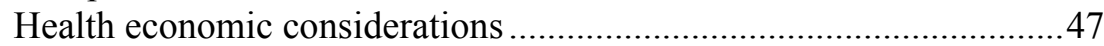

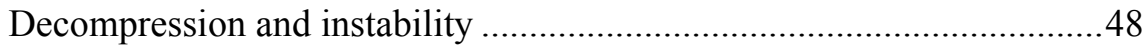

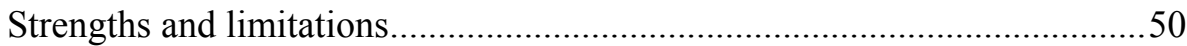

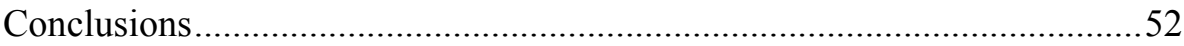

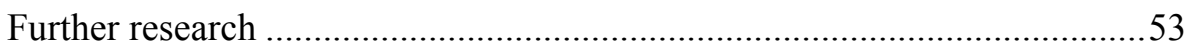

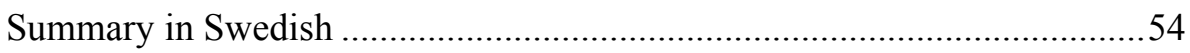

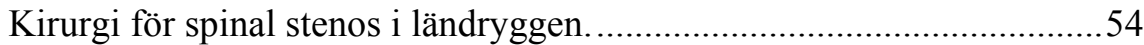

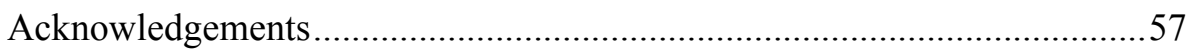

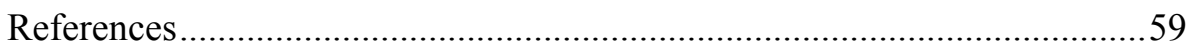





\section{Abbreviations}

$\begin{array}{ll}\text { ASA } & \text { American Society of Anestesiologists (physical status) } \\ \text { 3DCT } & \text { Three-Dimensional CT } \\ \text { 6MWT } & \text { 6-Minute Walk Test } \\ \text { CI } & \text { Confidence Interval } \\ \text { CT } & \text { Computed Tomography } \\ \text { D } & \text { Decompression } \\ \text { DF } & \text { Decompression with Fusion } \\ \text { DS } & \text { Degenerative Spondylolisthesis } \\ \text { EQ-5D } & \text { The 5 - dimensional scale of the EuroQol } \\ \text { HRQoL } & \text { Health Related Quality of Life } \\ \text { IPD } & \text { Interspinous Process Device } \\ \text { LE } & \text { Laminectomy } \\ \text { LSS } & \text { Lumbar Spinal Stenosis } \\ \text { LT } & \text { Laminotomy } \\ \text { MCID } & \text { Minimal Clinical Iimportant Difference } \\ \text { MRI } & \text { Magnetic Resonance Imaging } \\ \text { ODI } & \text { Oswestry Disability Index } \\ \text { OR } & \text { Odds Ratio } \\ \text { PROM } & \text { Patient Reported Outcome Measures } \\ \text { RCT } & \text { Randomised Controlled Trial } \\ \text { RR } & \text { Risk Ratio } \\ \text { SD } & \text { Standard Deviation } \\ \text { SF-36 } & \text { Short Form survey, 36 items } \\ \text { SSSS } & \text { The Swedish Spinal Stenosis Study } \\ \text { VAS } & \text { Visual Analogue Scale } \\ \text { ZCQ } & \text { Zürich Claudication Questionaire } \\ & \end{array}$





\section{Introduction}

Lumbar spinal stenosis (LSS) is a condition that is clinically characterized by walking disability, back pain and radiating pain in the buttocks and lower extremities. Feelings of numbness and muscular weakness are also common. ${ }^{1,2}$ The symptoms are classified as pseudoclaudicatio or neurogenic claudicatio and need to be distinguished from genuine claudicatio or claudicatio intermittens caused by arterial insufficiency. Spinal stenosis is a medical condition in which the spinal canal narrows and compresses the neural structures, for LSS at the level of the lumbar spine. The anatomical structures causing this narrowing are of degenerative origin and thus the condition is more common in older people and rare in patients younger than 50 years.

Structures causing stenosis and thus compromising the function of the neural elements in the spinal canal are a bulging disc, a thickened ligamentum Flavum and osteophytes from osteoarthritic changes in the facet joint. ${ }^{3}$ Degeneration in the segment sometimes leads to a slip forward of the adjacent upper vertebra, i.e. degenerative spondylolisthesis (DS) ${ }^{4}$, which might be a contributing factor to the stenosis. The stenosis is most pronounced in the erect position of the spine (e.g., as in standing and walking). Kyphosis in the segment, like in flexion of the lumbar region from a sitting position or in a forward bending position, increases the space in the spinal canal and is usually providing relief of pain. The degenerative cascade leading to the development of spinal stenosis has been described by Kirkaldy-Willis in 1976.5

While the anamnesis of the patient is that which is likely to arouse the attentive clinician's suspicions of the condition, a diagnosis has to be confirmed radiologically. Various techniques have been used to visualise the narrowing of the spinal canal. An x-ray with contrast medium injected into the dural sac (myelography) was the first examination applied to detect stenotic segments. The cross section area of the spinal canal has been shown to correlate to clinical symptoms where an available space for the neural structures of less than $75 \mathrm{~mm}^{2}$ is considered as a confirmation of the diagnosis. ${ }^{6}$ The later introduction of computed tomography (CT) and magnetic resonance imaging (MRI, Figure 2) made it possible to perform visualisation of the dural sac in cross section. MRI is now the method of choice and should be used if no contraindications (e.g. pacemaker) for this method exists. If MRI is contraindicated the combined examination with CT and mye- 
lography can be performed. Recently other methods than measuring of the cross section area have been developed to verify impingement of neural structures in the spinal canal. One of these methods includes a grading of the sedimentation of nerve roots in cross section MRI imaging. The absence of sedimentation (i.e. nerve roots packed together) is considered a positive sedimentation sign and shown to be associated with symptoms of LSS. ${ }^{7,8}$

Unlike other spinal conditions, there are seldom any findings in clinical examination and no validated tests specific for spinal stenosis. However, in typical cases the symptoms can be provoked with the patient in standing position with lumbar hyperextension and relieved when the patient is asked to lean forward. ${ }^{1}$ A thorough clinical examination is essential in order to exclude differential diagnoses such as hip and knee arthrosis, arterial insufficiency and polyneuropathy. These conditions, which restrict function and are a cause of pain, are all common in elderly patients.

The prevalence of LSS is difficult to estimate because the symptoms can be diffuse and thus there is a need for radiological confirmation to establish the diagnosis. The annual rate of surgery for LSS in Sweden is 35-45 per 100000 inhabitants and there has been a yearly increase of $5-10 \%$ in the past decade. ${ }^{9}$ Many patients with LSS will in time require surgical intervention as a final treatment. ${ }^{10}$ Annually, 14 of 10000 persons older than 65 years in the USA undergo surgery for LSS, which is a fourfold increase compared with 1985. We also observe a similar trend in Europe, and LSS has become the most common indication for spine surgery in Sweden as well as in many other countries. ${ }^{11-14}$ The reason for the increased attention is assumed to be an aging population in combination with better availability of MRI. However, another reason is an increased desire among elderly to stay active.

LSS is expected to gain greater attention worldwide in the coming decades as a result of the phenomenon of population ageing. According to the United Nations, the per cent of older people ( $>60$ years) will grow from $11.7 \%$ in 2013 to $21.1 \%$ by 2050 . In numbers, this means an increase from 800 million older people in 2013 to 2 billion in $2050 .{ }^{15}$ Obviously, ageing at such an unprecedented rate would place tremendous strain on healthcare systems globally and it is of importance that efforts are made to determine which patients benefits most from surgery and that treatments are continuously evaluated and compared. Because the complexity and cost of surgery for the most commonly surgically treated spinal condition (i.e. LSS) have increased in the past decades, it is important to evaluate the various types of operations available. ${ }^{16}$ 


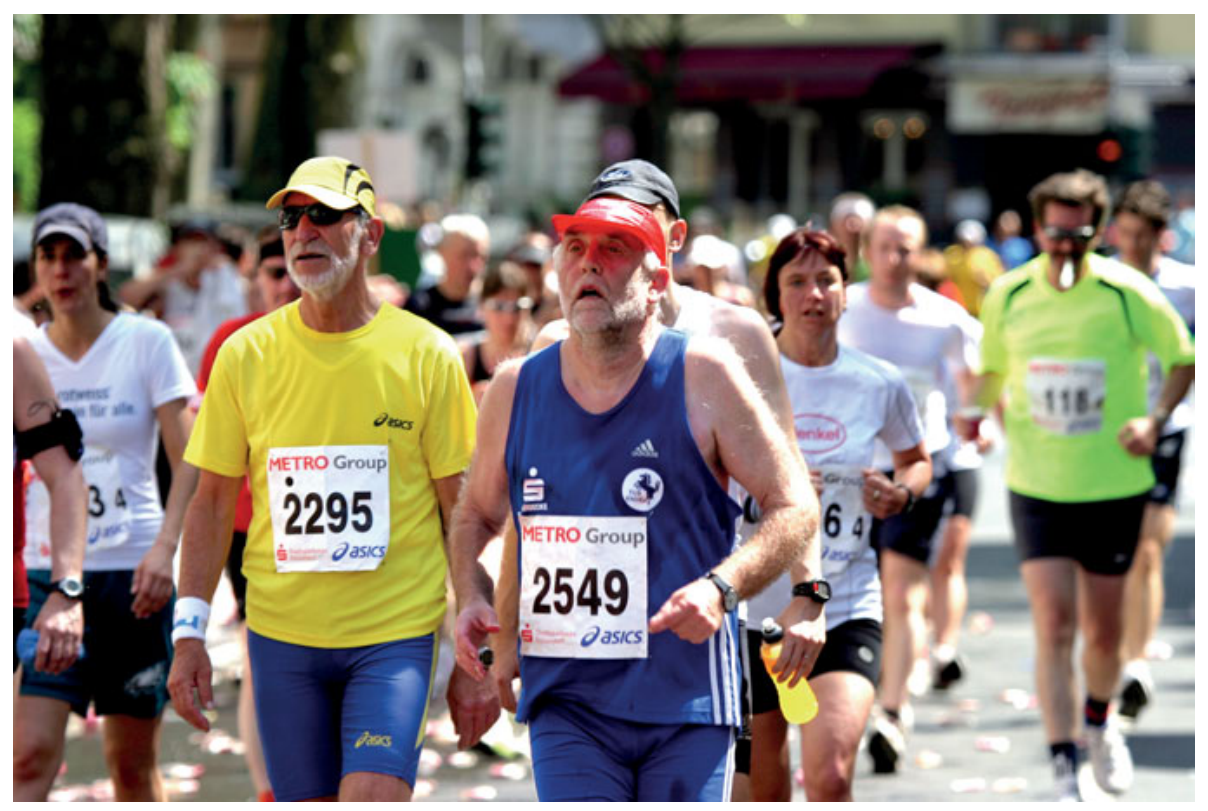

Figure 1. An ageing population and an increased desire among elderly to stay active are two determinants for why lumbar spinal stenosis has become the most common indication for back surgery.

\section{Non-surgical treatment}

There is well documented evidence for the superiority of surgery as opposed to non-surgical alternatives in the treatment of LSS. ${ }^{17-20}$ However, a conservative approach for up to 6 months can be recommended as there is a chance of improvement and a possibility the patient comes to recognise and accept the symptoms. ${ }^{21}$ The risk of sudden deterioration is very low and disastrous results from a non-surgical approach are seldom observed. ${ }^{22}$ Epidural steroid injections have been frequently used, especially in the US, but there is no robust evidence for its use. ${ }^{23}$ Physical activity in general and especially with the lumbar spine in a flexed position (which relieves pressure on the neural structures) like walking with trecking poles or bicycling might be beneficial and increase general health and function. A recent study in Sweden showed improvement of pain and function and a 50\% reduction in the desire for surgery in a group of LSS patients who trained regularly on a stationary bicycle for 4 months. ${ }^{24}$ 


\section{Surgical treatment}

Spinal stenosis was first described in 1949 by Professor Henk Verbiest, a Dutch neurosurgeon. Since then, recent decades have witnessed a rapid development from the original decompression of the neural structures with removal of most of the posterior elements of the spinal segment to increasingly complex surgery that includes various instrumented fusions.

Classic access to the spinal canal to decompress the neural structures is a central approach to remove the interspinous ligaments, parts of the spinal processes, lamina and the medial part of the facet joint (laminectomy, LE). An alternative is to perform the decompression by preserving the interspinal structures in the midline with a lateral approach removing part of the lamina bilaterally (laminotomy, LT) or unilaterally with reach of the ipsilateral osteophytes "over the top" of the dural sac. As compared with LE, LT is a more time-consuming and challenging technique with a higher risk of neural complications. $^{25}$

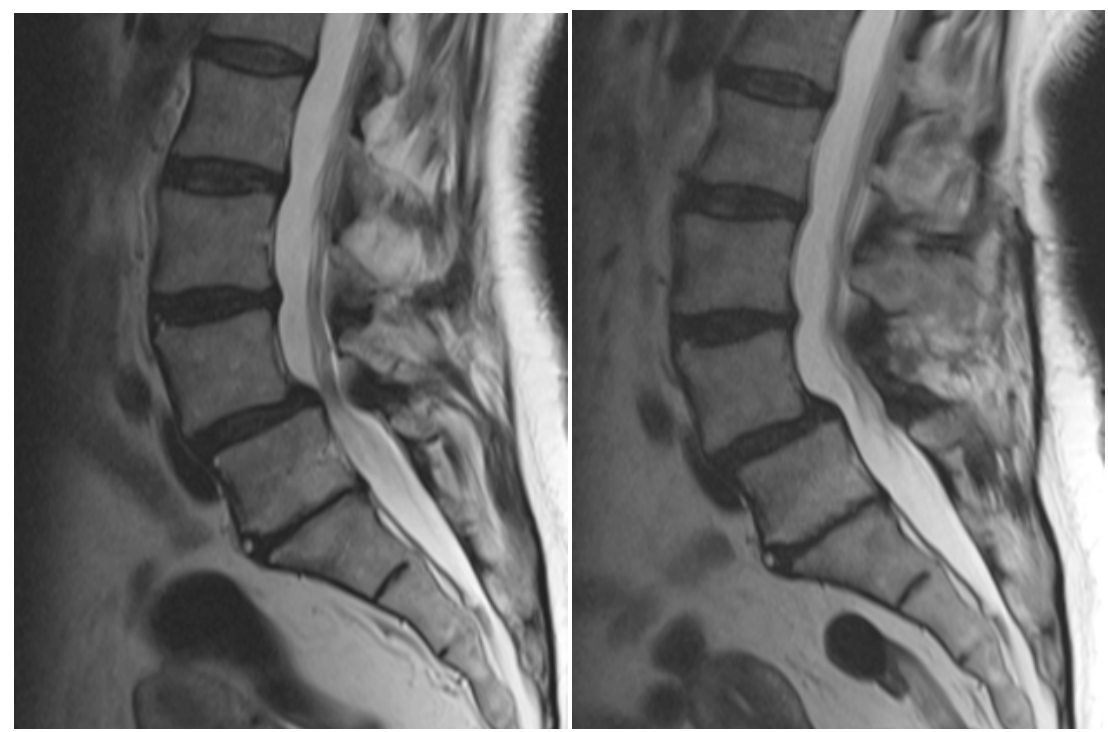

Figure 2. Magnetic resonance imaging (MRI) of the lumbar spine showing spinal stenosis with degenerative spondylolisthesis (DS) at the L4/5 segment before (left) and 2 years after (right) surgery with decompression without fusion.

If fusion is done as a supplement to decompression, the aim would be to acquire stability by bridging bone between the two vertebrae in the decompressed segment. The classic and original method (posterolateral fusion, PLF) is to place autologous bone from the iliac crest between the transverse processes and immobilise the lumbar region with a brace for some months. ${ }^{26}$ In the 1970s, Roy-Camille introduced instrumentation with pedicle screws and rods or plates to connect the vertebrae in a stable construct ${ }^{27}$ (Figure 3). 
This procedure accelerated the use of fusion and later on more complex techniques were developed that created interbody fusion between the endplates in the disc space (posterior lumbar interbody fusion, PLIF and transforaminal lumbar interbody fusion, TLIF).

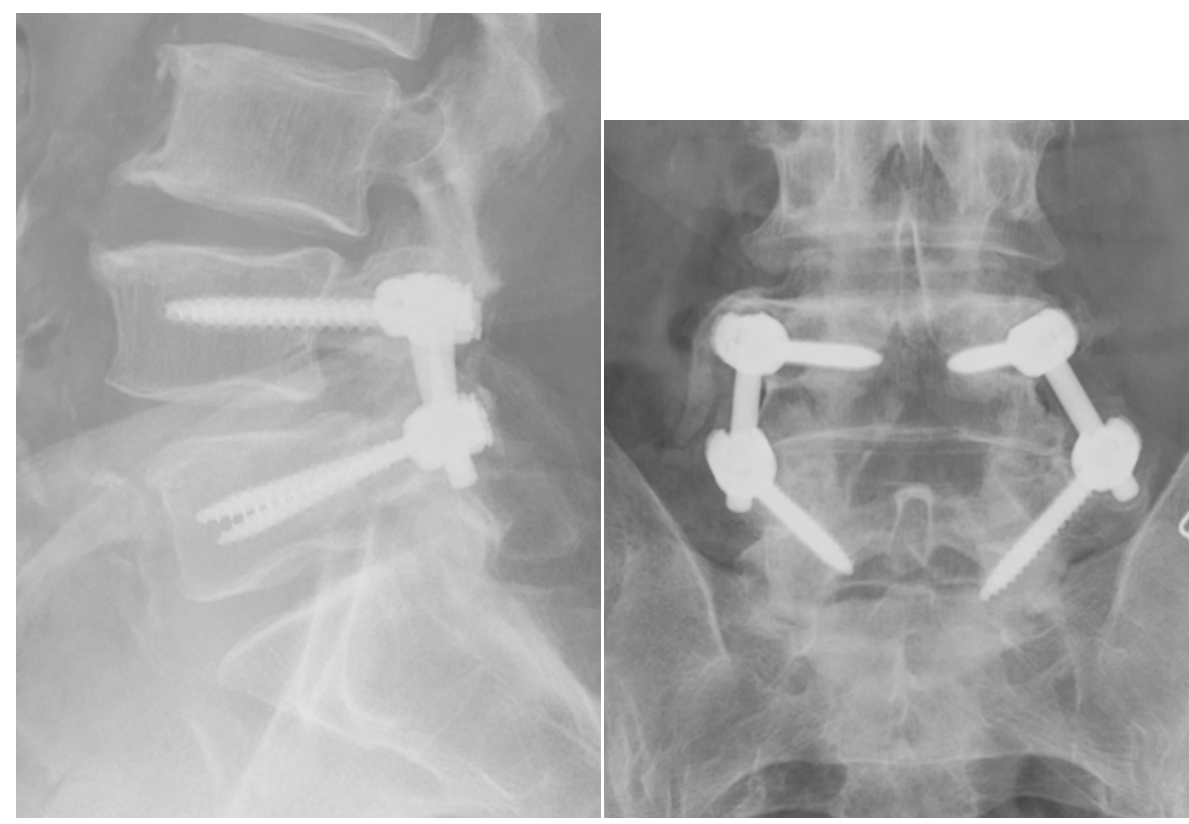

Figure 3. Instrumented fusion as a complement to decompression in spinal stenosis with degenerative spondylolisthesis (DS) at the L4/5 segment 2 years after surgery.

Biomechanical studies have revealed a correlation between the extent of decompression and post-operative instability ${ }^{28,}{ }^{29}$ Studies have also revealed that post-operative spondylolisthesis, which indicates instability, might occur after decompression. ${ }^{30,31}$ However, possible clinical consequences of a preoperatively existent DS or a slipped vertebra as an effect of spinal decompressive surgery have been under debate for decades. ${ }^{30,}{ }^{32}$ The presence of pre-operative DS has been considered a presumptive risk of instability and progressed slip after decompression. During the past few decades, surgical procedures for LSS have tended to become more complex. Decompression of the neural structures with laminectomy (LE) has increasingly been supplemented with lumbar fusion with the intention to minimise the potential risk of future instability and deformity. Fusion for many surgeons has been considered as mandatory as a complement to decompression in LSS with a pre-operative DS. ${ }^{33,} 34$ In the US, there was an increase of $60 \%$ in fusion surgeries for LSS between 2004 and 2009, whereas decompression alone (D) had only a $45 \%$ increase during the same period. ${ }^{35}$ This increase in complex surgery has been reported to be associated with more complications as well as higher costs. ${ }^{13,36}$ In elderly patients with a high proportion of comorbid 
conditions, a higher mortality rate has been indicated ${ }^{37}$, and an increased risk of life-threatening complications ${ }^{13}$ has been demonstrated when fusion is added to the decompression. Another argument against the more extensive procedure of fusion is the debate on the risk of accelerated degenerative changes adjacent to a lumbar fusion. ${ }^{38,39}$ This risk has been found to be particularly relevant for older patients and for patients operated on for LSS. ${ }^{39,40}$ In the literature, there is weak support for the widespread use of fusion in patients with LSS, regardless of whether there is pre-operative DS or not. ${ }^{41}$,

${ }^{42}$ The natural course of untreated DS has been reported to be benign and without correlation between progression of slip and clinical symptoms. ${ }^{43,44}$

In recent years, new surgical techniques for LSS have been developed. One technique involves indirect decompression of the stenotic segment by distraction and kyphosis. An interspinous process device (IPD) is implanted between the vertebral spinous processes. The device leads to tightening of the ligamentum flavum and thereby thinning of this structure, which in turn leaves more space in the spinal canal. This procedure has the advantage that the implant can be inserted under local anaesthesia, which is of benefit for patients with cardiac or pulmonary conditions where general anesthesia is a risk. However, several studies have reported inferior results (mostly related to a high frequency of repeated surgery) with the IPD compared with standard conventional surgical decompression. ${ }^{45},{ }^{46}$ However, the minimally invasive IPD can be an alternative in old patients with a high risk of severe complications related to anaesthesia and with incapacitating symptoms of LSS. Another technique that has been used to partially stabilise a segment after decompression is the various systems for pedicle screw-based posterior dynamic stabilisation. These systems, however, have been found to be associated with a high number of mechanical failures without better clinical outcome than decompression or fusion. ${ }^{47,48}$ None of these newer surgical techniques will be discussed in this thesis.

\section{Outcome of surgery}

Patients with LSS often have very low pre-operative health-related quality of life (HRQoL) ${ }^{49,}{ }^{50}$ In general, $60-80 \%$ of all surgically treated patients with LSS report a satisfactory outcome. ${ }^{51}$ This means that up to $20-40 \%$ report dissatisfaction with the surgical results and remaining disabilities in the legs or back are not uncommon ${ }^{52}$ In elderly populations, there are often comorbidities that, additional to the LSS, can restrict function and ambulation. Reasons for the reported low degree of satisfaction might be unrealistic patient expectations and that LSS is caused by the development of normal degenerative changes, a process that continues on operated and adjacent lumbar segments even after surgery. On the group level, several studies have reported superior results compared with conservative treatment and a signifi- 
cant improvement in relevant patient-reported outcome measures (PROMs) at follow-up compared with pre-operatively. ${ }^{17-20}$ Strong predictors of an inferior outcome have been identified as low pre-operative walking ability and depression. Other identified negative predictors are cardiovascular disorder and spinal deformity (scoliosis). ${ }^{53-55}$ On the other hand, high self-reported general health, good pre-operative walking ability and a pronounced stenosis on pre-operative radiological examination are factors reported to predict a superior outcome. ${ }^{53}$

Tobacco smoking has been found to be a significant risk factor for complications and an inferior clinical result after surgery. Smoking is associated with impaired tissue healing and an increased risk of pulmonary and cardiovascular complications in orthopaedic surgery ${ }^{56-58}$ Negative effects of smoking on the spine and on results of spinal surgery have been demonstrated. For instance, smoking increases the risk for lumbar disc degeneration and inhibits lumbar spinal fusion. ${ }^{59,60}$ 


\section{Aims}

The overall aims of this thesis on surgery for lumbar spinal stenosis (LSS) are twofold:

1. To evaluate which method of surgery that generally can be considered to give sufficiently good results with regards to reduced pain and improved function with the least costs and risk of adverse events and complications.

2. To evaluate whether there is a difference in outcome between smokers and non-smokers.

The specific aims of the thesis are presented separately below for each paper:

Paper I: Evaluate whether there is a difference in clinical outcome between smokers and non-smokers after surgery for LSS.

Paper II-III: Investigate whether complimentary fusion improves clinical outcome in decompressive surgery for LSS, with or without pre-operative degenerative spondylolisthesis (DS).

Paper III: Determine whether decompression plus fusion (DF) is costeffective compared with decompression alone (D) in LSS, with or without DS.

Paper IV: Evaluate instability after decompression for LSS with DS using either removal of the midline structures with laminectomy (LE) or preservation of these structures by bilateral laminotomy (LT). 


\section{Materials and methods}

In all studies included in this thesis, the National Swedish Register for Spine Surgery (Swespine) was used to collect patient-reported outcome measures pre-operatively and at follow-up. Swespine, started in 1993, is a prospective registration of surgery for spinal disorders. The register covers more than $80 \%$ of the total number of surgical procedures for degenerative lumbar spine disorders in Sweden. ${ }^{11}$ Before surgery, patients are asked to complete questions pertaining to pre-operative data, such as the Oswestry Disability Index (ODI) ${ }^{61}$ back and leg pain according to the visual analogue scale (VAS), Short Form 36 (abbreviated health survey, SF-36), ${ }^{62}$ EuroQol (quality of life, EQ-5D) ${ }^{63}$, smoking habits, consumption of analgesics, working conditions and eventual sick-listing. Estimated walking capacity is recorded as one of four categories $(<100 \mathrm{~m}, 100-500 \mathrm{~m}, 500-1000 \mathrm{~m}$ and $>1000$ $\mathrm{m})$. Questionnaires with the same content plus questions on global assessment and satisfaction with the treatment are used for follow-up 1,2, 5 and 10 years after surgery. The current protocol of the register has been validated in a test-retest situation and can reliably detect post-operative improvements among large groups of patients. ${ }^{11,64}$ The questionnaires, which are sent to the patients with a pre-paid envelope, are unrelated to any visit to hospital and completed without assistance of the surgeon or any other person involved in the treatment. The surgeons' contribution to the register is to make the diagnosis and to classify LSS as central or lateral (foraminal) stenosis. The possible existence of pre-operative degenerative spondylolisthesis (DS) in LSS patients is noted and defined as existing if it is estimated to $3 \mathrm{~mm}$ or more on current radiological examination. Details on surgical technique and any implants as well as perioperative complications are also recorded by the surgeon.

All studies were approved by the Regional Ethical Review Boards: Paper IIII was approved by the board in Uppsala and paper IV by the board in Stockholm. 


\section{Paper I}

Data were obtained for all patients in Swespine that were operated on for central LSS before October 1, 2006. Of the 8024 patients with a diagnosis of central LSS, the personal identification numbers (PINs) were invalid in 40 patients. These 40 patients were excluded, leaving 7984 patients. The remaining 7984 patients had undergone surgery at 48 hospitals. In 7 of these 48 hospitals, follow-up procedures had failed and none of the patients from these 7 hospitals passed the 2-year follow-up. The 428 patients who had undergone surgery in these 7 hospitals were excluded, leaving 7556 patients. The accuracy of the diagnosis of central LSS in the register was assessed in a sample of 295 patients from three institutions by two of the authors (BS and $\mathrm{PF}$ ). This assessment found that the diagnoses were inclined to be less accurate in the youngest patients. The most common error was that a big herniated disc, narrowing the spinal canal but without other degenerative changes contributing to a compression of neural structure, was diagnosed as LSS instead of as disc herniation. This misclassification was not a problem in patients aged $>50$ years. Therefore, 424 patients $<50$ years of age at the time of surgery were excluded, resulting in 7132 patients. Of these 7132 patients, 5057 (71\%) had completed the 2-year follow-up. The 2075 patients that did not complete the 2-year follow-up did not differ from the patients who completed the 2-year follow-up in age, sex, or baseline values for ODI, SF-36, EQ-5D and walking ability. In the 5057 patients that completed the follow-up, data on smoking habits were missing in 502, leaving a final sample of 4555 patients for the analysis. The 502 patients in which smoking data were missing did not differ from the study group in age, sex or results of the surgery. Figure 4 is a flow chart of patients who met criteria for inclusion in the study.

Statistical calculations were performed using SAS software, version 9.1 (SAS Institute, Cary, NC). For continuous dependent variables, adjusted means in smokers and non-smokers were estimated using the GLM (general linear model) procedure in the SAS package. For dichotomous dependent variables, multivariable logistic regression was applied to assess odds ratios (ORs) with 95\% confidence intervals (CIs). The models were adjusted for age, sex and baseline regular use of analgesics (use/no use), as well as by baseline values of the continuous outcome variables. Paper I served as an introduction to register studies for the authors. 


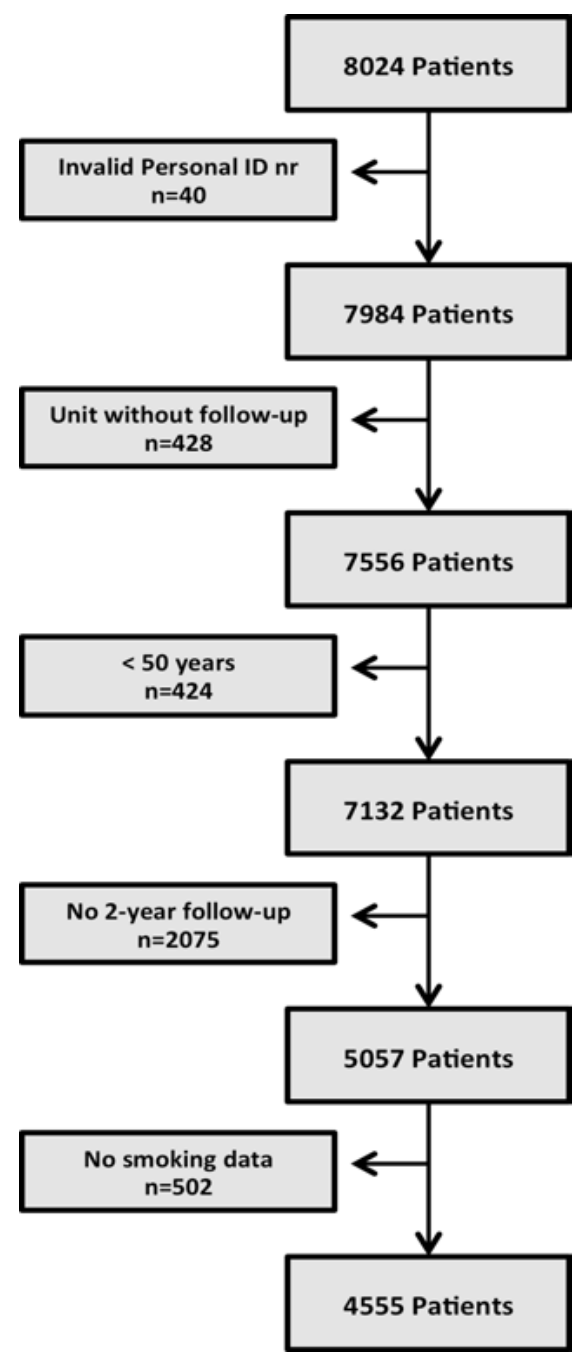

Figure 4. Flow diagram of the inclusion of patients in the study (Paper I).

\section{Paper II}

Data were obtained for all patients in Swespine aged $\geq 50$ years at the time of surgery that were operated on for central LSS on one or two adjacent levels between L2 and L5 from January 1, 1998 to July 1, 2008. Patients with and without pre-operative DS were included. In all, 8785 patients fulfilled these criteria. Surgery had been done at 48 hospitals. In seven of these hospitals, the follow-up procedures had failed and none of the patients from these seven hospitals passed the 2-year follow-up. The 643 patients who had undergone surgery in these seven hospitals were excluded, leaving 8142 eligi- 
ble patients. Of these 8142 patients, 5390 (66\%) had completed the 2-year follow-up. The 2752 patients who failed to complete the 2-year follow-up did not differ from the patients who completed the 2-year follow-up in age distribution, sex or baseline values for back pain, leg pain, ODI or EQ-5D.

Validation of the incidence of pre-operative DS in the register was performed. For this purpose, pre-operative radiological examinations of 167 patients from three hospitals were analysed by two of the authors (PF and BS) who were blinded to the information in the register. The last radiological examination (MRI, CT or plain x-ray) before surgery was analysed. The assessments of the two observers were concordant in $84 \%$ of the cases and the information in the register agreed with the assessment of at least one of the observers in $87 \%$ of the cases.

In the calculation of repeated surgery, a re-operation was defined as a second operation in the same segment as the index level, a subsequent operation in another part of the lumbar spine for the diagnosis of central LSS or a lumbar operation for post-operative instability. For technical reasons and reasons related to the research ethics permit, such as that the patient's personal identification number was not allowed to be used, estimation of the number and type of re-operations could not be done on exactly the same material as the patient-reported outcome at the 2-year follow-up. However, the cohort used for the calculation of the frequency of repeated surgery was very similar to, and included, the cohort used for the other variables. All patients in Swespine operated for LSS before July 1, 2008 at an age $\geq 50$ years were used in the calculation of subsequent re-operations, regardless of operated levels or whether they had completed the 2-year follow-up. These criteria were fulfilled by 9651 patients who were then included in the estimation of re-operations.

Statistical calculations were performed using SAS, version 9.1 (SAS Institute, Cary, NC, USA) in a similar way as in Paper I but with the purpose to compare results from $\mathrm{D}$ with those from $\mathrm{DF}$. The models were adjusted for age, sex, smoking, duration of symptoms, previous spine surgery, baseline analgesic use, and additionally, baseline values for the studied outcome variable. To compensate for possible differences in patient selection and surgical technique between hospitals, a frailty component was included as a random-effect parameter in all models to handle within-hospital dependencies.

\section{Paper III}

Seven hospitals in Sweden participated in the open-label RCT the Swedish Spinal Stenosis Study (Uppsala University Hospital, Stockholm Spine Center, Spine Center Gothenburg and the regional hospitals in Falun, Eskilstuna, Ängelholm and Sundsvall). Sample size calculation was made with a power 
of $80 \%$ and a relevant detectable difference between samples was set to $\geq 12$ for ODI and $\geq 20$ for VAS, leading to a minimum of 40 patients in each subgroup to be analysed. Patients referred with the diagnosis of central LSS were assessed for eligibility in accordance with the inclusion and exclusion criteria listed in Table 1.

After providing oral and written informed consent, patients were randomly assigned, in a 1:1 ratio in those with and in those without DS, either to DF or to D. Randomisation was performed by means of an online randomization module and was stratified for DS. Before randomisation, the patient population was examined for the existence of DS (defined as $\geq 3 \mathrm{~mm}$ slip on conventional lateral X-ray). DS was measured as described by Stokes and Frymoyer. ${ }^{65}$ The enrollment process is shown Figure 5.

Outcome was collected from Swespine with the addition of the Zurich Claudication Questionnaire (ZCQ), which is a condition-specific outcome measure. ${ }^{66,67}$ The primary outcome measure was the ODI. ${ }^{61}$ The ZCQ consists of three domains: symptom severity, physical function and patient satisfaction. The subscale scores are the averages of the points obtained for every question of the subscale, with a maximum score of 5 for symptom severity and 4 for physical function and patient satisfaction. Higher scores indicate increasing disability. A decrease of at least 0.5 points on the symptom severity scale and on the physical function scale is defined as a good result, as is a score of less than 2.5 on the patient satisfaction subscale. ${ }^{68}$ In addition to the patient-reported outcome measures, an objective analysis, a 6-minute walk test (6MWT) ${ }^{69,70}$ of the patients' ambulatory capacity was performed. In this test, supervised by a physiotherapist or nurse, the patient walked a marked distance of $25 \mathrm{~m}$ back and forth and the result was ground covered in meters during 6 minutes. Information about complications and re-operations were collected from the patients' medical files and from Swespine. The follow-up period was 2 years. The randomisation period was from October 2006 to June 2012.

To evaluate cost-effectiveness, patient-reported quality of life (QoL) was measured with the EQ-5D, where 0 represents "death" and 1 perfect QoL. These data were collected together with estimates of direct and indirect costs. Direct costs included number of visits to health care units, length of hospital stay, surgical costs and prescription of pharmaceuticals. Indirect costs comprised sick leave, work force, out-of-pocket expenses and number of days that other family members assisted the patient. Resource use variables at follow-ups were all patient-reported. Relevant data were collected at baseline and 6,12 and 24 months following surgery. Costs for surgery were obtained from one clinic (Stockholm Spine Center) and used as a proxy for all participating clinics. Prices are presented in 2014 SEK.

Analysis at follow-up was made on the whole study group and separately on the subgroups with and without pre-operative DS. Continuous variables were tabulated and analysed using ordinary descriptive summary measures. 
Changes from baseline and differences between the two treatment groups were analysed using Student's t test. Ordinal variables were tabulated descriptively but also dichotomised and analysed using standard summary measures based on $2 \times 2$-tables. In addition, we calculated relative risks (RR) with $95 \%$ confidence intervals by comparing outcomes of the DF group to the D group. Analysis was made both with and without stratification on DS. SAS version 9.3 and Stata 11 were used for analysing the data. Missing data for economic variables were estimated using multiple imputation ${ }^{71-73}$ with $\mathrm{m}=5$. Baseline values for age, sex, back and leg pain (VAS), ODI and EQ5D were used to create the imputation model.

Table 1. Inclusion and exclusion criteria for eligibility (Paper III).

\begin{tabular}{|c|c|}
\hline Inclusion criteria & Exclusion criteria \\
\hline $\begin{array}{l}\text {-Pseudoclaudication in one or both legs } \\
\text { and backpain (VAS }>30)\end{array}$ & -Spondylolysis \\
\hline $\begin{array}{l}\text {-MRI with } 1-2 \text { adjacent stenotic seg- } \\
\text { ments (area } \leq 75 \mathrm{~mm} 2 \text { ) between L2 and } \\
\text { sacrum }\end{array}$ & $\begin{array}{l}\text {-Degenerative lumbar scoliosis (Cobb } \\
\text { angle }>20 \mathrm{deg} \text { ) }\end{array}$ \\
\hline -Duration of symptoms $>6$ months & $\begin{array}{l}\text {-History of lumbar spinal surgery for } \\
\text { spinal stenosis or instability }\end{array}$ \\
\hline \multirow[t]{5}{*}{-Written informed consent } & $\begin{array}{l}\text {-Stenosis not caused by degenerative } \\
\text { changes }\end{array}$ \\
\hline & -Stenosis caused by herniated disc \\
\hline & $\begin{array}{l}\text {-Other specific spinal conditions, } \mathrm{Mb} \\
\text { Bechterew, malignancy, neurologic disor- } \\
\text { ders }\end{array}$ \\
\hline & $\begin{array}{l}\text {-History of vertebral compression frac- } \\
\text { tures in affected segments }\end{array}$ \\
\hline & $\begin{array}{l}\text {-Psychological disorders where the sur- } \\
\text { geon considers participation inappropri- } \\
\text { ate(dementia, drug abuse) }\end{array}$ \\
\hline
\end{tabular}




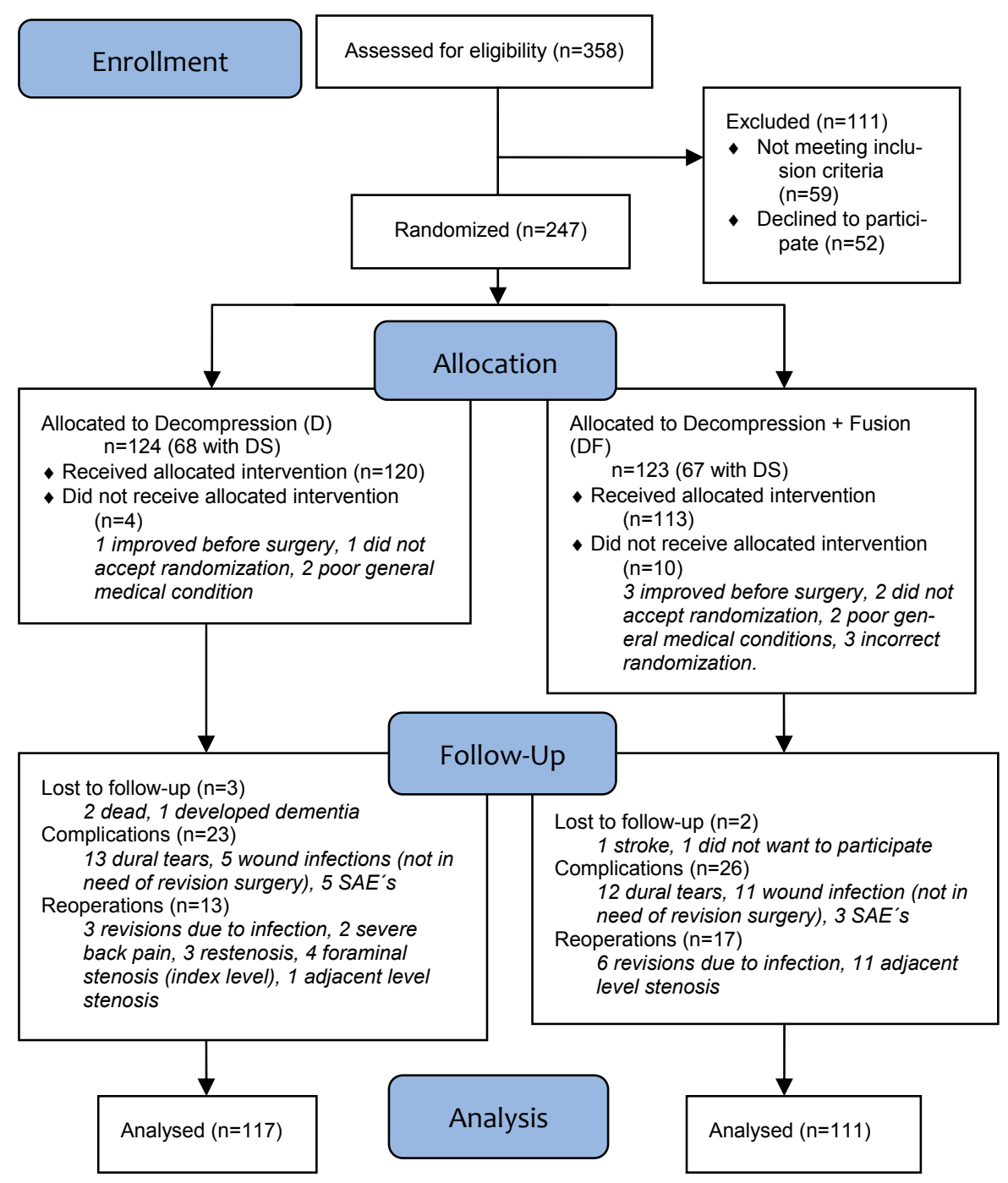

Figure 5. Flow diagram of the enrollment process. DS= degenerative spondylolisthesis. SAE = severe adverse event (e.g. myocardial infarction, stroke and thromboembolic disease) (Paper III).

\section{Paper IV}

Patients aged 50-75 years with typical symptoms of LSS (pseudoclaudication and back pain) and MRI findings of central LSS with concomitant DS $\geq 3 \mathrm{~mm}$ in one or two adjacent lumbar levels between L3 and L5 were assessed for participation in the study. Both written and oral information of the study were given. If an informed consent were obtained, randomisation was 
done between decompression with removal of the midline structures, laminectomy (LE) and decompression with preservation of these structures, i.e. bilateral laminotomies (LT). 23 patients (13 women, 10 men) were included in the study.

Each patient was examined before and 6 months after surgery. No additional medication was given before the examinations. Each examination comprised two CT scans: provoked flexion and provoked extension. The patients were placed on a custom made jig (OT-Center, Danderyd, Sweden) incorporating different blocks for provoking the lumbar spine into flexion and extension directions. A provocation of the spine was made in supine position for extension and in prone position for flexion (Figure 6). The patients were gradually provoked in the jig up to maximal flexion or extension. A clinical spiral CT unit (Somatom Definition AS, Siemens, Erlangen, Germany) was used to examine the patients. Slices were reconstructed at $0.60 \mathrm{~mm}$ increments. The average radiation effective dose was calculated to be $1.4 \mathrm{mSv}$ per scan. Spatial registrations of CT data and subsequent measurement of vertebral movement were performed using a semi-automated 3D volume fusion tool, which has been described in previous publications. ${ }^{74-77}$ This tool presents a graphical user interface to pick co-homologous points (landmarks) in the moving "target" (flexion) volume and the stationary "reference" (extension) volume. These landmarks can be picked on orthogonal planar axial, coronal and sagittal slices using a point landmark or a true 3D sphere. After successful registration, the two CT data volumes are in nearly the same position in a single coordinate system.

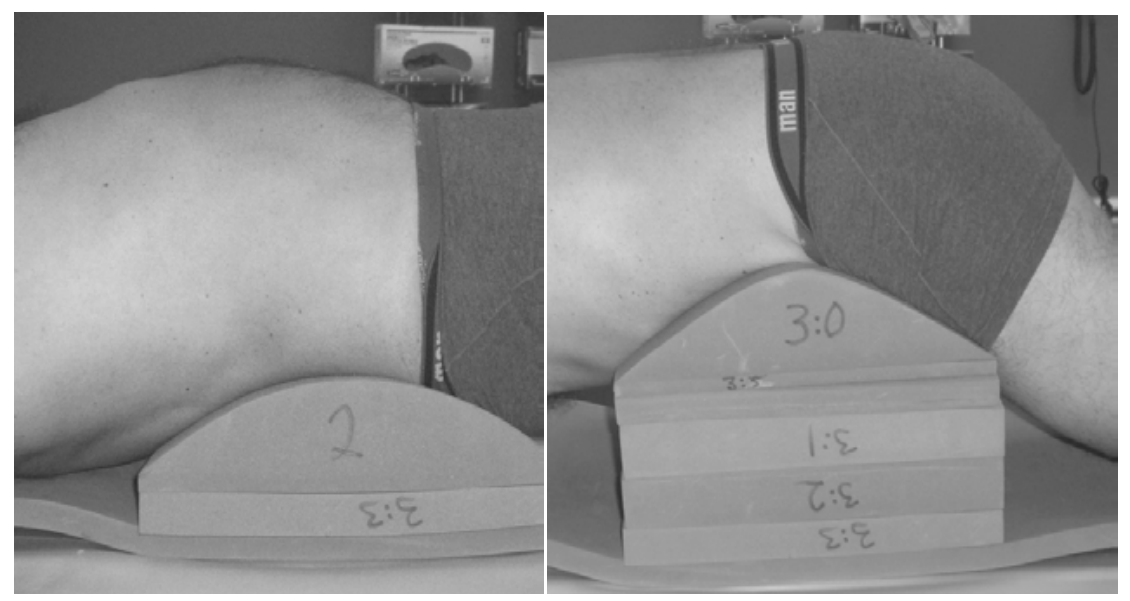

Figure 6. Provoked extension and flexion of the lumbar spine. (Paper IV)

All rotations and translations were calculated in this coordinate system. Movement in the DS segment between extension and flexion examinations before and 6 months after surgery was assessed as follows using a 3D volume fusion tool restricted to a rigid body transformation. The CT extension 
and flexion data volumes before and 6 months post-surgery were registered by using the lower vertebrae in the DS segment. We placed nine cohomologous landmarks in the vertebra in each of the extension and flexion $\mathrm{CT}$ volumes. To create a stable rigid body, care was taken to spread the landmarks in 3D throughout the vertebrae. Figure 7 illustrates the CT volumes and the rigid body formation. The rigid body transformation generated both a rotation and translation matrix for the matched extension and flexion volumes. The registration generated transformation matrices that corresponded to the movement of the upper vertebrae in the DS segment between extension and flexion. There were then two sets of data, the movement between extension and flexion before surgery and 6 months after surgery. We subtracted the values of rotation in each plane and in each translational direction to obtain the difference in movement resulting from the operation. The analysis was performed by one of the authors (PS) who is very familiar with this method. The accuracy of the method is $0.6 \mathrm{~mm}$ for translation and 1.0 degree for rotation in $3 \mathrm{D}$ and in all cardinal planes.

The data were first tested for normality (Gaussian distribution) using histograms, box, density and quantile/quantile plots. Student's T test was applied between the difference values in each rotational and translational direction to determine whether there was a difference between the two methods. Further, an ANOVA was performed on the two methods and all the rotation and translation results. The open source statistical package $\mathrm{R}$ version 3.0.2 was used for all statistical calculations. ${ }^{78}$

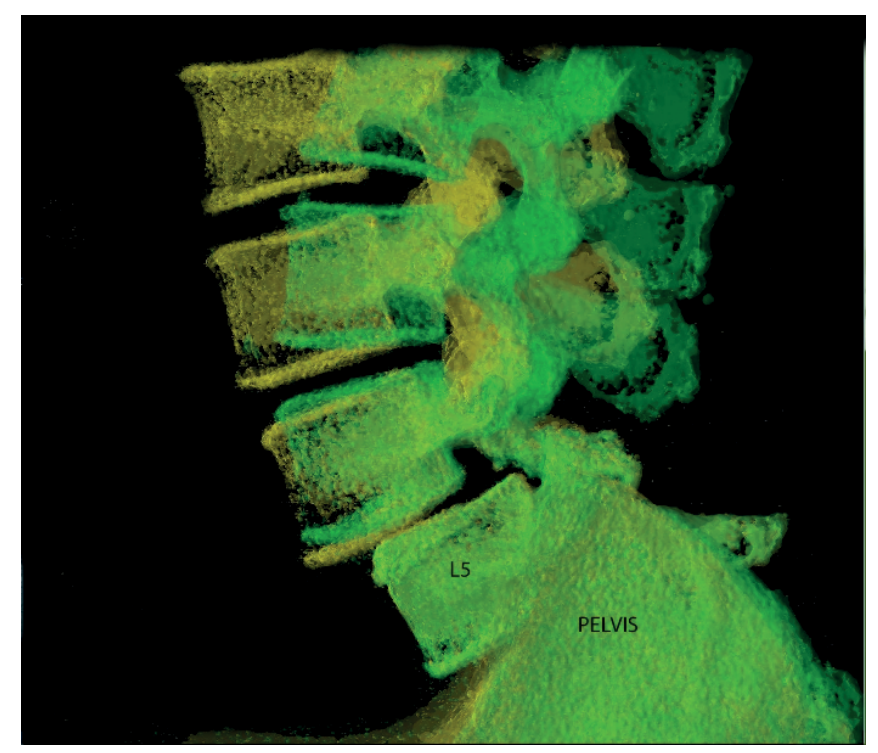

Figure 7. Computed Tomography (CT) volumes in flexion (yellow) and extension (green). The two volumes are merged into a rigid body consisting of L5. (Paper IV) 


\section{Results}

\section{Paper I}

Of the 4555 patients included in the analysis, $758(17 \%)$ were smokers at the time of surgery. Patient characteristics in relation to smoking status are described in Table 2. Smokers were younger than non-smokers and tended to have slightly more disability symptoms before surgery.

Independent of differences in baseline characteristics, the results after surgery were inferior in smokers compared with non-smokers (Table 3) for the generic and condition-specific outcome measures studied (EuroQol, ODI, SF-36 PF physical functioning and SF-36 BP bodily pain). Moreover, smokers experienced more pain at the 2-year follow-up.

The non-smoking group had a more positive attitude toward the results of the surgery: $63 \%$ of the non-smokers were satisfied compared with $54 \%$ of the smokers. Adjusted OR for dissatisfaction in smokers was $1.79(95 \% \mathrm{CI}$ 1.51-2.12), indicating that smokers had a $79 \%$ higher risk than non-smokers of being dissatisfied after surgery. The inferior results in smokers compared with non-smokers were evident both after decompression with fusion (OR $1.87,95 \%$ CI 1.29-2.70) and decompression alone (OR 1.75, 95\% CI 1.422.14). Return to work was studied in patients aged $\leq 60$ years at operation and not retired or on disability pension. In this group, $36 \%$ of the smokers and $51 \%$ of the non-smokers returned to work. The adjusted OR for a smoker not to return to work was 1.78 (95\% CI 1.21-2.61). Regular use of analgesics was more frequent in smokers at the 2-year follow-up, even though there was no difference between smokers and non-smokers in use before surgery $(p=0.68)$. At follow-up, $40 \%$ of the smokers and $30 \%$ of the non-smokers used analgesics $(p<0.0001)$. The multivariable-adjusted OR for regular use of analgesics in smokers was 1.86 (95\% CI 1.55-2.23).

Before surgery, walking ability of the smokers was significantly lower than walking ability of the non-smokers despite the lower age of the smokers $(p<0.0001)$. Nevertheless, the effects of surgery on improvement of walking ability were inferior in smokers than in non-smokers, expressed as the OR for smokers to improve 1, 2 or 3 classes in walking ability compared with non-smokers. The significant adjusted ORs, displayed in Figure 8, were $0.82,0.69$ and 0.65 for 1,2 or 3 classes respectively, indicating that the probability for improvement was significantly lower in the smoking group, particularly for major improvements. 
Table 2. Clinical and demographic characteristics of the study population of smokers and non-smokers at baseline. SF-36 BP/PF=Short Form survey, 36 items Bodily Pain/Physical Functioning. (Paper I).

\begin{tabular}{|c|c|c|}
\hline & SMOKERS & NON-SMOKERS \\
\hline & $n=758$ & $\mathrm{n}=3797$ \\
\hline Female & $444(58.6 \%)$ & 2091 (55.1\%) \\
\hline Male & $314(41.4 \%)$ & $1706(44.9 \%)$ \\
\hline $\begin{array}{l}\text { Analgesics } \\
\text { (Regular use) }\end{array}$ & $54.1 \%$ & $53.3 \%$ \\
\hline \multicolumn{3}{|l|}{ Walking distance } \\
\hline$<100 \mathrm{~m}$ & $43.4 \%$ & $46.3 \%$ \\
\hline $100-500 m$ & $39.2 \%$ & $30.7 \%$ \\
\hline $500-1000 m$ & $11.3 \%$ & $12.4 \%$ \\
\hline$>1000 \mathrm{~m}$ & $6.2 \%$ & $10.7 \%$ \\
\hline \multirow[t]{2}{*}{$\begin{array}{l}\text { Fusion included in } \\
\text { surgery }\end{array}$} & $23 \%$ & $23 \%$ \\
\hline & & \\
\hline Age & $64.6(8.5)$ & $70.0(8.6)$ \\
\hline Back pain (VAS) & $60(26)$ & $57(27)$ \\
\hline Leg pain (VAS) & $66(24)$ & $63(25)$ \\
\hline EuroQol & $0.30(0.31)$ & $0.35(0.31)$ \\
\hline $\begin{array}{l}\text { Oswestry Disability } \\
\text { Index }\end{array}$ & $46(15)$ & $45(16)$ \\
\hline SF-36 BP & $25(15)$ & $27(16)$ \\
\hline SF-36 PF & $30(18)$ & $32(21)$ \\
\hline
\end{tabular}


Table 3. Results with crude and adjusted means with 95\% confidence intervals (CI) at the 2-year follow-up. *Corrected for age, sex, use of analgesics and differences at baseline for the studied outcome variable (Paper I).

\begin{tabular}{|c|c|c|}
\hline & Crude & Adjusted* \\
\hline \multicolumn{3}{|l|}{ EuroQol (EQ-5D) } \\
\hline Smokers & $0.55(0.52-0.57)$ & $0.55(0.52-0.57)$ \\
\hline Non-smokers & $0.61(0.60-0.62)$ & $0.61(0.60-0.62)$ \\
\hline \multicolumn{3}{|l|}{ Oswestry Disability Index } \\
\hline Smokers & $33(30-34)$ & $33 \quad(31-35)$ \\
\hline Non-smokers & $29(28-30)$ & $29(28-29)$ \\
\hline \multicolumn{3}{|l|}{ SF-36 PF } \\
\hline Smokers & $47(44-49)$ & $44 \quad(42-47)$ \\
\hline Non-smokers & $51(50-52)$ & $52(51-53)$ \\
\hline \multicolumn{3}{|l|}{ SF-36 BP } \\
\hline Smokers & $45 \quad(43-48)$ & $46 \quad(43-47)$ \\
\hline Non-smokers & $51 \quad(50-52)$ & $51 \quad(50-52)$ \\
\hline \multicolumn{3}{|l|}{ Leg pain (VAS) } \\
\hline Smokers & $41 \quad(39-44)$ & $43(41-45)$ \\
\hline Non-smokers & $35(34-36)$ & $35(34-37)$ \\
\hline \multicolumn{3}{|l|}{ Back pain (VAS) } \\
\hline Smokers & $42(39-44)$ & $43(40-44)$ \\
\hline Non-smokers & $34(33-35)$ & $34(33-35)$ \\
\hline
\end{tabular}




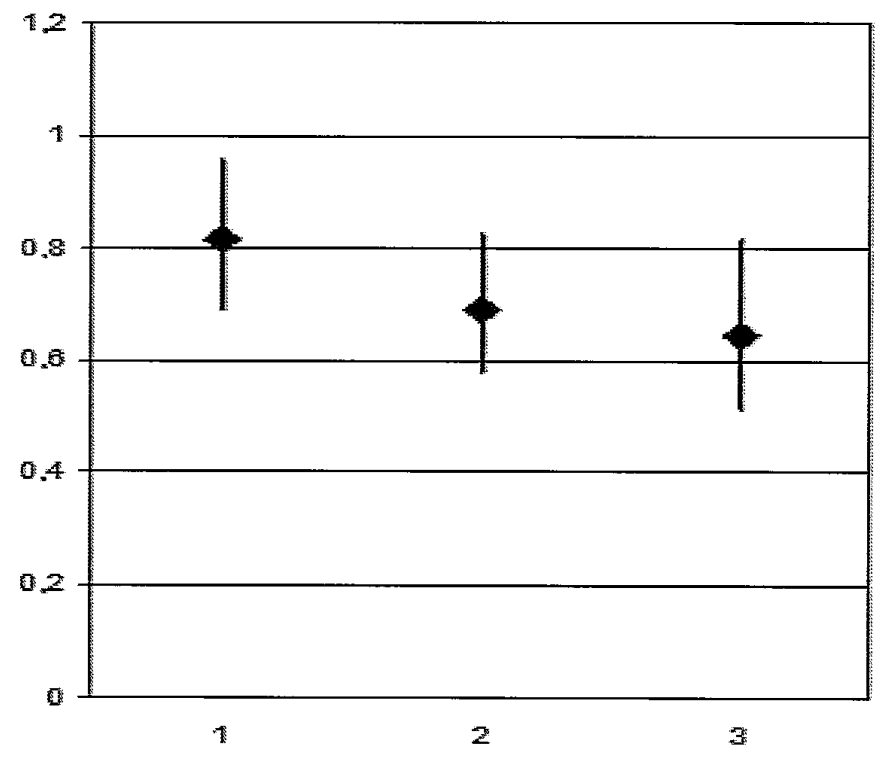

Figure 8. Odds Ratios (ORs) for smokers to improve 1, 2 or 3 classes in self reported walking capacity (Swespine) compared with non-smokers. The bars indicate 95\% CI. (Paper I)

\section{Paper II}

In all, 4259 patients (79\%) were treated with D and 1131 (21\%) had combined DF. Pre-operatively, the patients in the DF group had a higher proportion of women, expressed more back pain and a higher percentage of DS. Most fusions were instrumented $(\mathrm{n}=933,82.5 \%)$. Totally, 1306 patients (24\%) had DS pre-operatively. In all, 651 patients $(50 \%)$ with DS and 480 $(12 \%)$ without had a fusion. More patients with pre-operative DS were female $(\mathrm{n}=956,73 \%)$ than those without $(\mathrm{n}=2101,51 \%)$. The mean VAS for back pain was similar in patients with and without pre-operative DS (58 vs. 55). Table 4 shows the pre-operative characteristics of the patients.

At the 2-year follow-up, significant improvements were noted for all outcome measures, regardless of surgical method or the presence of DS. There were no differences in the mean EQ-5D or ODI after both forms of surgical treatment, irrespective of the presence of DS pre-operatively (Table 5). In the two subgroups with and without pre-operative DS, there were no differences in the mean scores for back or leg pain between the two treatment groups at the 2-year follow-up. Further, no differences were observed in analgesic use: $32 \%$ of the patients in both groups regularly used analgesics (1343 in the D group and 362 in the DF group). However, when the subgroups are pooled, the large sample size produces a significant value in the 
difference in back pain $(p=0.04)$ but with minimal difference in VAS and with overlapping confidence intervals (34.6-36.7 for the D group vs. 31.335.2 for the DF group).

There were no differences in the odds of improvement of self reported walking ability or overall satisfaction between the two treatment groups. Compared with D, those treated with DF had an adjusted OR of $1.01(95 \%$ CI 0.85-1.19) for having improved walking ability and an adjusted OR of 1.08 (95\% CI 0.94-1.24) for satisfaction (self-evaluated) with the surgical outcome.

No difference could be detected between the results following instrumented and non-instrumented fusion. The adjusted OR for patient satisfaction was 0.98 (95\% CI 0.55-1.74) when instrumented fusion was compared with non-instrumented fusion. The same comparison rendered an adjusted OR of 1.01 (95\% CI 0.73-1.40) for the regular use of analgesics.

The rate of subsequent surgery for spinal stenosis or post-operative instability was 7.0\% (95\% CI 6.4-7.6) after D $(\mathrm{n}=7407)$ and $8.1 \%(95 \%$ CI 7.0 9.2) after DF $(\mathrm{n}=2337)$.The mean time between the first and second procedures was 27 months (range 4 days to 11 years). 
Table 4. Table 4. Baseline demographics of the patients by procedure and presence of pre-operative degenerative spondylolisthesis $(D S)$. $D=$ decompression alone. $D F=$ decompression with fusion.(Paper II)

\begin{tabular}{|c|c|c|c|c|}
\hline \multirow[t]{2}{*}{ Baseline characteristics } & \multicolumn{2}{|l|}{ Procedure } & \multicolumn{2}{|c|}{ Pre-operative DS } \\
\hline & DF & D & No & Yes \\
\hline n (\%) & $\mathrm{n}=1131$ & $\mathrm{n}=4259$ & $\mathrm{n}=4084$ & $\mathrm{n}=1306$ \\
\hline Mean age (range) & $67(50-90)$ & $70(50-91)$ & $69(50-91)$ & $69(50-90)$ \\
\hline Females & $818(72)$ & $2239(53)$ & $2101(51$ & $956(73)$ \\
\hline Smokers & 204 (18) & $723(17)$ & $692(17)$ & $235(18)$ \\
\hline Prior spine surgery & $175(17)$ & $608(17)$ & $604(15)$ & $179(14)$ \\
\hline DS & $667(59)$ & $639(15)$ & - & - \\
\hline Fusion & - & - & $480(12)$ & $651(50)$ \\
\hline \multicolumn{5}{|l|}{ Levels operated: } \\
\hline L2-L3 & $2 \%$ & $3 \%$ & - & - \\
\hline L2-L4 & $3 \%$ & $7 \%$ & - & - \\
\hline L3-L4 & $11 \%$ & $13 \%$ & - & - \\
\hline L3-L5 & $29 \%$ & $34 \%$ & - & - \\
\hline \multirow[t]{2}{*}{ L4-L5 } & $55 \%$ & $47 \%$ & - & - \\
\hline & \multicolumn{4}{|c|}{ Mean (SD) } \\
\hline Back pain (VAS) & $61(25)$ & $54(27)$ & $55(27)$ & $58(26)$ \\
\hline Leg pain (VAS) & $62(26)$ & $63(25)$ & $63(25)$ & $62(25)$ \\
\hline EuroQol & $0,33(0.31)$ & $0,36(0.32)$ & $0.36(0.32)$ & $0.36(0.31)$ \\
\hline Oswestry Disability & $46(15)$ & $44(16)$ & $44(16)$ & $45(15)$ \\
\hline \multicolumn{5}{|l|}{ Index } \\
\hline Years to follow up & 2.1 & 2.1 & 2.1 & 2.1 \\
\hline
\end{tabular}


Table 5. Results at the 2-year follow-up. Values are means with 95\% confidence intervals (CIs) adjusted for age, gender, smoking habits, use of analgesics and differences at baseline for the studied outcome variable. $D S=$ degenerative spondylolisthesis. $D=$ decompression alone. $D F=$ decompression with fusion.(Paper II)

\begin{tabular}{|c|c|c|c|c|}
\hline & Leg pain (VAS) & $\begin{array}{c}\text { Back pain } \\
\text { (VAS) }\end{array}$ & EQ-5D & ODI \\
\hline \multicolumn{5}{|c|}{ No preop DS } \\
\hline $\begin{array}{l}\mathrm{D} \\
\mathrm{n}=3596\end{array}$ & $\begin{array}{c}36 \\
(35-37)\end{array}$ & $\begin{array}{c}36 \\
(34-36)\end{array}$ & $\begin{array}{c}0,61 \\
(0,60-0,63)\end{array}$ & $\begin{array}{c}28 \\
(27-29)\end{array}$ \\
\hline \multirow[t]{2}{*}{$\begin{array}{l}\mathrm{DF} \\
\mathrm{n}=488\end{array}$} & $\begin{array}{c}37 \\
(34-40)\end{array}$ & $\begin{array}{c}34 \\
(32-37)\end{array}$ & $\begin{array}{c}0,6 \\
(0,57-0,64)\end{array}$ & $\begin{array}{c}29 \\
(26-31)\end{array}$ \\
\hline & $\mathrm{p}=0,69$ & $\mathrm{p}=0,30$ & $\mathrm{p}=0,56$ & $\mathrm{p}=0,45$ \\
\hline \multicolumn{5}{|c|}{ Preop DS } \\
\hline $\begin{array}{l}\mathrm{D} \\
\mathrm{n}=617\end{array}$ & $\begin{array}{c}35 \\
(32-37)\end{array}$ & $\begin{array}{c}35 \\
(32-37)\end{array}$ & $\begin{array}{c}0,63 \\
(0,61-0,66)\end{array}$ & $\begin{array}{c}27 \\
(26-29)\end{array}$ \\
\hline \multirow[t]{2}{*}{$\begin{array}{l}\mathrm{DF} \\
\mathrm{n}=689\end{array}$} & $\begin{array}{c}32 \\
(30-35)\end{array}$ & $\begin{array}{c}32 \\
(30-34)\end{array}$ & $\begin{array}{c}0,62 \\
(0,59-0,64)\end{array}$ & $\begin{array}{c}27 \\
(26-29)\end{array}$ \\
\hline & $\mathrm{p}=0,17$ & $\mathrm{p}=0,12$ & $\mathrm{p}=0,34$ & $\mathrm{p}=0,93$ \\
\hline \multicolumn{5}{|c|}{ All patients } \\
\hline $\begin{array}{l}\mathrm{D} \\
\mathrm{n}=4213\end{array}$ & $\begin{array}{c}36 \\
(35-37)\end{array}$ & $\begin{array}{c}36 \\
(35-37)\end{array}$ & $\begin{array}{c}0,62 \\
(0,61-0,63)\end{array}$ & $\begin{array}{c}28 \\
(27-28)\end{array}$ \\
\hline \multirow[t]{2}{*}{$\begin{array}{l}\mathrm{DF} \\
\mathrm{n}=1177\end{array}$} & $\begin{array}{c}35 \\
(33-37)\end{array}$ & $\begin{array}{c}33 \\
(31-35)\end{array}$ & $\begin{array}{c}0,61 \\
(0,59-0,63)\end{array}$ & $\begin{array}{c}28 \\
(27-29)\end{array}$ \\
\hline & $\mathrm{p}=0,57$ & $\mathrm{p}=0,04 *$ & $\mathrm{p}=0,33$ & $\mathrm{p}=0,69$ \\
\hline
\end{tabular}

\section{Paper III}

Baseline data are presented in Table 6. There were no differences between the two treatment groups in any of the pre-operative variables. Patients stratified to the group with pre-operative DS had a mean pre-operative slip of $7.4 \mathrm{~mm}$ (SD 2.7) with a maximum of $14.3 \mathrm{~mm}$. All patients randomized to DF had a central decompression in combination with fusion. Of 113 fusions, $102(90 \%)$ had instrumented posterolateral fusion, 6 instrumented interbody fusion, and 5 uninstrumented fusion. Of the decompressions in the D group, $98(82 \%)$ were central decompressions, i.e. excision of the spinal midline structures (laminectomy) and 22 were bilateral laminotomies with preservation of the midline structures. Levels operated on were lumbar segments L45 (49\%), L3-5 (33\%), L3-4 (10\%), L2-4 (4\%), L4-S1 (3\%), and L2-3 (1\%). 
Table 6. Baseline characteristics. DF=decompression with fusion, $D=$ decompression alone. ASA= physical status classification according to American Society of Anestesiologists. ZCQ=Zürich Claudication Questionaire. 6MWT=6minute walk test. (Paper III)

\begin{tabular}{|c|c|c|c|c|c|}
\hline & & \multicolumn{2}{|c|}{$\begin{array}{l}\text { No degenerative } \\
\text { spondylolisthesis }\end{array}$} & \multicolumn{2}{|c|}{$\begin{array}{c}\text { Degenerative spondylo- } \\
\text { listhesis (DS) }\end{array}$} \\
\hline & & $\begin{array}{c}\mathbf{D F} \\
n=46\end{array}$ & $\underset{n=52}{\mathbf{D}}$ & $\begin{array}{c}\mathbf{D F} \\
n=67\end{array}$ & $\underset{n=68}{\mathbf{D}}$ \\
\hline Age & Years, Mean (SD) & $66(9)$ & $66(8)$ & $68(7)$ & $67(7)$ \\
\hline Gender & Female n $(\%)$ & $19(41)$ & $29(56)$ & $51(76)$ & $56(82)$ \\
\hline Smoker & $\mathrm{n}(\%)$ & $7(15)$ & $9(17)$ & $9(13)$ & $10(15)$ \\
\hline Slip (DS) & mm, Mean (SD) & - & - & $7.4(2.6)$ & $7.4(2.8)$ \\
\hline \multirow[t]{2}{*}{$\begin{array}{l}\text { Physical status } \\
\text { (ASA) }\end{array}$} & $\begin{array}{l}\text { Healthy or mild systemic } \\
\text { disease (ASA } 1 \text { or } 2) \mathrm{n}(\%)\end{array}$ & $38(83)$ & $46(88)$ & $57(85)$ & $53(78)$ \\
\hline & $\begin{array}{l}\text { Severe systemic disease } \\
(\text { ASA 3) } n(\%)\end{array}$ & $8(17)$ & $6(12)$ & $10(15)$ & $15(22)$ \\
\hline ODI & Mean (SD) & $43(15)$ & $41(15)$ & $41(13)$ & $41(14)$ \\
\hline EQ-5D & Mean (SD) & $0.40(0.31)$ & $0.37(0.31)$ & $0.39(0.31)$ & $0.36(0.30)$ \\
\hline Back pain (VAS) & Mean (SD) & $59(24)$ & $61(25)$ & $64(20)$ & $63(24)$ \\
\hline Leg pain (VAS) & Mean (SD) & $65(19)$ & $61(24)$ & $64(21)$ & $65(22)$ \\
\hline \multirow[t]{2}{*}{ ZCQ } & $\begin{array}{l}\text { Symptom severity, Mean } \\
\text { (SD) }\end{array}$ & $3.4(0.72)$ & $3.5(0.69)$ & $3.4(0.6)$ & $3.5(0.5)$ \\
\hline & Physicalfunction, Mean (SD) & $2.4(0.63)$ & $2.5(0.55)$ & $2.6(0.5)$ & $2.5(0.5)$ \\
\hline 6MWT & Meters, Mean (SD) & $312(155)$ & $331(129)$ & 309 (117) & $313(110)$ \\
\hline
\end{tabular}

For both interventions, a significant improvement was found in all generic outcome measures at the 2-year follow-up. Primary outcome measure, function according to the ODI showed improvement in the whole material of 15 units in the DF group and 17 units in the D group $(p=0.36)$. The difference in ODI between the groups was -2.2 (95\% CI -6.9-2.6). Of the patients in the DF group, 61\% reported satisfaction with the outcome of the surgery compared with $64 \%$ in the D group $(\mathrm{RR}=0.96$; 95\% CI: 0.78-1.17). Back pain was reported to have decreased in $80 \%$ of the patients in the DF group, which can be compared with $77 \%$ in the D group, $R R=1.04$ (95\% CI: 0.91 1.19). Leg pain was reported to have decreased in $81 \%$ of the patients in the $\mathrm{DF}$ group and $74 \%$ in the $\mathrm{D}$ group, $\mathrm{RR}=1.10$ (95\% CI: 0.96-1.27). Outcomes in relation to the presence or absence of DS are given in Table 7. A subanalysis of patients with a DS exceeding the mean slip of $7.4 \mathrm{~mm}(\mathrm{n}=69)$ showed no difference in ODI between the two treatment groups, neither at baseline nor at follow-up. In this patient subset, ODI at follow-up was 25 after both DF and D ( $\mathrm{p}=0.98)$, and back pain VAS 36 after DF and 32 after $\mathrm{D}(\mathrm{p}=0.55)$. 
Walking ability. In the whole population, $89 \%$ in the DF group and $84 \%$ in the D group self-reported an improvement in walking ability of at least 1 step in the four-category scale for self-estimated walking ability in Swespine (RR 1.06, 95\% CI 0.96-1.18) (Table 7). Pre-operatively, 13\% of all patients reported a walking ability $>1 \mathrm{~km}$. At the 2-year follow-up, this proportion had increased to $54 \%$ with no differences between the treatment groups (data not shown). The 6MWT revealed significantly increased walking distance at follow-up when compared with pre-operative levels; however, no differences could be detected between the treatment groups (83 meters in the DF group and 78 meters in the D group, $p=0.82$ ) (Figure 9). In the subgroup with pre-op DS, increased walking distance was 73 meters in the DF group and 83 meters in the $\mathrm{D}$ group $(p=0.60)$ (Table 7).

Complications. Dural tears occurred in 25 patients: $12(11 \%)$ in the DF group and in 13 in the $\mathrm{D}$ group (11\%). The number of post-operative wound infections in need of antibiotics was $11(10 \%)$ in the DF group and $5(4 \%)$ in the D group. Severe adverse events (e.g., myocardial infarction, stroke and thromboembolic disease) occurred in 3 patients in the DF group and in 5 patients in the $\mathrm{D}$ group.

Re-operations. The number of patients having subsequent lumbar surgery within 2 years post-operatively was $17(15 \%)$ in the DF group and $13(11 \%)$ in the $\mathrm{D}$ group. Indications for re-operation are summarised in Table 8. There was no significant difference in re-operation rate between the groups (RR 1.39, 95\% CI 0.71-2.73). At the 2-year follow-up, an additional 3 patients were planned for surgery, 1 in the DF group (pseudarthrosis) and 2 in the D group (restenosis and severe back pain). Among DS patients specifically, 12 patients in the DF group (18\%) and 7 in the D group (10\%) had subsequent surgery.

Economic evaluation. 232 patients agreed to participate in the health economic (HE) evaluation and 213 (92\%) had at least one follow-up visit (thus, 19 patients did not participate). There were no significant differences in baseline values and perioperative variables between these 19 nonparticipating patients and the 213 patients included in the health economic (HE) evaluation. We therefore conclude that dropout was random.

QoL (EQ-5D) at baseline (SD) was and $0.39(0.31)$ in the DF group and 0.37 $(0.30)$ in the $\mathrm{D}$ group $(\mathrm{p}=0.53)$. After 12 and 24 months, there was no significant difference in QoL between the two groups: 0.66 in both groups (SD 0.30 and 0.29 respectively) at 12 months $(\mathrm{p}=0.86)$, and $0.63(0.31)$ and 0.65 $(0.31)$ in the $\mathrm{DF}$ and $\mathrm{D}$ groups respectively at 24 months $(\mathrm{p}=0.45)$. Variables describing resource use are presented in Table 8. The same amount of resources in both groups was consumed pre-operatively. In the context of direct costs (mainly hospital costs including surgery), DF was more expen- 
sive than $\mathrm{D}$ for three reasons, namely extra operation time, longer hospital stay and implant cost. Patients in the DF group stayed more than three days longer in hospital after surgery than patients in the D group. In the 2-year period after surgery, resource use was not statistically different between the DF and D groups (indirect costs): for instance, some indirect costs included number of visits to physicians, visits to other health care professionals, total number of days for any kind of social benefits and use of painkillers for back pain. The re-operation rate in the two groups was also similar.

Sensitivity analyses analysing patients with and without DS separately showed similar results (results omitted). 
Table 7. Results from the 2-year follow-up post-operatively. Quantitative variables with means (SD) and p-values. Qualitative variables with proportions and risk ratios (RRs) with 95\% confidence intervals (CIs). D=decompression, $D F=$ decompression with fusion.(Paper III)

\begin{tabular}{|c|c|c|c|c|c|c|c|}
\hline & & \multicolumn{3}{|c|}{ No degenerative spondylolisthesis } & \multicolumn{3}{|c|}{$\begin{array}{c}\text { Degenerative spondylolisthe- } \\
\text { sis(DS) }\end{array}$} \\
\hline & & $\begin{array}{c}\mathbf{D F} \\
n=44\end{array}$ & $\underset{n=51}{\mathbf{D}}$ & & $\begin{array}{c}\mathbf{D F} \\
n=67\end{array}$ & $\underset{n=66}{\mathbf{D}}$ & \\
\hline Outcome & & \multicolumn{2}{|c|}{ Means (SD) } & $p$ & \multicolumn{2}{|c|}{ Means (SD) } & $p$ \\
\hline $\begin{array}{l}\text { Operating } \\
\text { time }\end{array}$ & Minutes & $150(47)$ & $80(28)$ & $<0.01$ & $149(44)$ & $95(40)$ & $<0.01$ \\
\hline Bleeding & $\mathrm{ml}$ & $648(498)$ & $288(319)$ & $<0.01$ & $686(434)$ & $311(314)$ & $<0.01$ \\
\hline ODI & & $29(20)$ & $27(18)$ & 0.70 & $25(19)$ & $21(18)$ & 0.11 \\
\hline EQ-5D & & $0.62(0.31)$ & $0.59(0.35)$ & 0.85 & $0.63(0.31)$ & $0.69(0.28)$ & 0.20 \\
\hline $\begin{array}{l}\text { Back } \\
\text { pain(VAS) }\end{array}$ & & $41(32)$ & $45(31)$ & 0.66 & $36(29)$ & $26(25)$ & 0.15 \\
\hline $\begin{array}{l}\text { Leg } \\
\text { pain(VAS) }\end{array}$ & & $35(31)$ & $34(33)$ & 0.46 & $32(30)$ & $29(31)$ & 0.60 \\
\hline \multirow[t]{3}{*}{ ZCQ } & $\begin{array}{l}\text { Symptom } \\
\text { severity }\end{array}$ & $2.6(1.0)$ & $2.5(1.1)$ & 0.41 & $2.4(0.9)$ & $2.4(1.0)$ & 0.56 \\
\hline & $\begin{array}{l}\text { Physical } \\
\text { function }\end{array}$ & $1.9(0.7)$ & $1.8(0.8)$ & 0.20 & $1.8(0.8)$ & $1.7(0.7)$ & 0.53 \\
\hline & $\begin{array}{l}\text { Patient } \\
\text { satisfac- } \\
\text { tion }\end{array}$ & $2.2(0.9)$ & $2.1(0.9)$ & 0.65 & $2.1(0.9)$ & $1.9(0.8)$ & 0.22 \\
\hline \multirow[t]{2}{*}{ 6MWT } & Meters & 417 (163) & $416(130)$ & 0.38 & $382(152)$ & $396(144)$ & 0.60 \\
\hline & & \multicolumn{2}{|c|}{ Proportions } & $\begin{array}{c}\text { RR } \\
(95 \% \mathrm{CI})\end{array}$ & \multicolumn{2}{|c|}{ Proportions } & $\begin{array}{c}\text { RR } \\
(95 \% \mathrm{CI})\end{array}$ \\
\hline $\begin{array}{l}\text { Overall } \\
\text { satisfaction }\end{array}$ & $\begin{array}{l}\mathrm{n}(\%) \\
\text { satisfied }\end{array}$ & $23(52)$ & $27(53)$ & $\begin{array}{c}0.99 \\
(0.67-1.45)\end{array}$ & $43(64)$ & $45(68)$ & $\begin{array}{c}0.94 \\
(0.74-1.20)\end{array}$ \\
\hline $\begin{array}{l}\text { Global as- } \\
\text { sessment }\end{array}$ & $\begin{array}{l}\mathrm{n}(\%) \\
\text { improved }\end{array}$ & & & & & & \\
\hline Back pain & & $33(75)$ & $33(65)$ & $\begin{array}{c}1.16 \\
(0.89-1.51)\end{array}$ & $53(79)$ & $54(82)$ & $\begin{array}{c}0.97 \\
(0.82-1.14)\end{array}$ \\
\hline Leg pain & & $36(82)$ & $35(69)$ & $\begin{array}{c}1.19 \\
(0.94-1.50)\end{array}$ & $52(78)$ & $48(73)$ & $\begin{array}{c}1.07 \\
(0.88-1.30)\end{array}$ \\
\hline $\begin{array}{l}\text { Walking } \\
\text { ability } \\
\text { (self reported) }\end{array}$ & $\begin{array}{l}\mathrm{n}(\%) \\
\text { improved }\end{array}$ & $40(91)$ & $41(80)$ & $\begin{array}{c}1.13 \\
(0.96-1.33)\end{array}$ & $59(88)$ & $57(86)$ & $\begin{array}{c}1.02 \\
(0.90-1.16)\end{array}$ \\
\hline
\end{tabular}




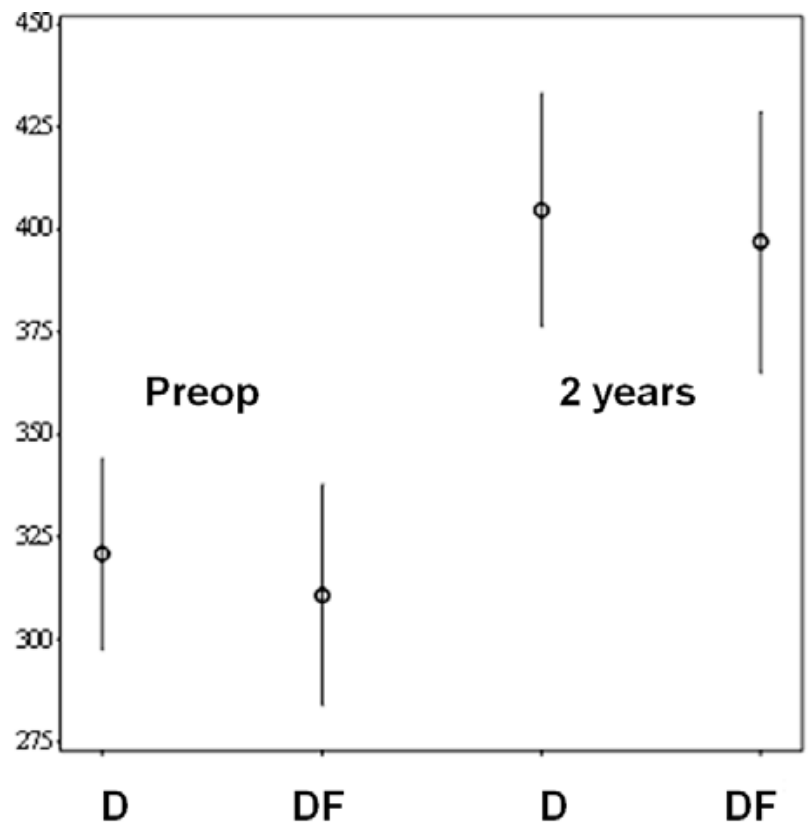

Figure 9. The 6-minute walk test (6MWT) for all patients in the study, regardless of degenerative spondylolisthesis (DS), pre-op and at follow-up after 2 years. $\mathrm{D}=\mathrm{de}-$ compression, $\mathrm{DF}=$ decompression + fusion. The bars indicate $95 \%$ confidence intervals (CI). (Paper III)

Table 8. Re-operations within the 2-year follow-up period. DF=decompression with fusion, $D=$ decompression alone. (Paper III)

\begin{tabular}{lcc}
\hline Indication for reoperation & All patients & D \\
& $n=113$ & $n=120$ \\
& 5 & 3 \\
Early revision (<3mo) due to infection & 1 & \\
Late revision( $>3 \mathrm{mo})$ due to infection & & 2 \\
Severe back pain & & 3 \\
Restenosis & & 4 \\
Foraminal stenosis (index level) & 11 & 1 \\
Adjacent level stenosis & $17(15 \%)$ & $13(11 \%)$ \\
Total & & \\
\hline
\end{tabular}


Table 9. Resource use within the 2-year follow-up for all patients participating in the health economic (HE) evaluation. Data for all patients regardless of preoperative degenerative spondylolisthesis (DS). DF=decompression with fusion, $D=$ decompression alone. (Paper III)

\begin{tabular}{lccc}
\hline & DF & D & \\
\hline $\begin{array}{l}\text { Perioperative } \\
\text { Length of stay, days (SD) }\end{array}$ & $\mathrm{n}=113$ & $\mathrm{n}=119$ & \\
Operation cost, SEK & $7.4(8.4)$ & $4.1(6.1)$ & $p<0.001$ \\
& 101300 & 44900 & \\
& $(=12200$ USD) & $(=5400$ USD) & \\
& & & \\
$\begin{array}{l}\text { Follow up } \\
\text { Number of visit to doctor (SD) }\end{array}$ & $\mathrm{n}=104$ & $\mathrm{n}=109$ & \\
$\begin{array}{l}\text { Number of visit to other health care profes- } \\
\text { sionals (SD) }\end{array}$ & $13(3.3(3.3)$ & $1.8(5.3)$ & $p=0.49$ \\
$\begin{array}{l}\text { Total days on benefits of any kind (SD) } \\
\text { Still using pain killers, } \mathrm{n}(\%)\end{array}$ & $61(172)$ & $22(45)$ & $p=0.13$ \\
& $42(40)$ & $40(37)$ & $p=0.57$ \\
\hline
\end{tabular}

\section{Paper IV}

One patient was excluded because of moving artefact in the pre-operative CT scan, and two patients randomised to bilateral laminotomies (LT) were excluded because of dural tears by which the surgeon had to convert to laminectomy (LE) in order to be able to repair the dural defect. Visual analysis indicated that all registrations were able to be successfully performed. In the numeric analysis, the mean value for error of all the landmarks in the human vertebrae was within $2 \mathrm{CT}$ voxel values $(0.76 \mathrm{~mm})$. The mean difference in $3 \mathrm{D}$ rotation between examination post-surgery and at the 6-month follow-up was 0.7 degrees in the LE group and 0.25 degrees in the LT group $(p=0.79)$. For translation, the mean difference in the LE group was $1.10 \mathrm{~mm}$ and in the LT group $0.15 \mathrm{~mm}(p=0.42)$. Student's t test confirmed that means did not differ significantly between the two methods for any of the rotations or translations. An ANOVA demonstrated that there was no difference between the two methods $(F=0.8 ; p=0.5)$. An examination of the residuals showed that the two methods were independent and normally distributed. In Table 10, rotation and translation are presented for the LE and LT groups before and after surgery. Clinical outcome from Swespine is presented in Table 11. There were significant improvements in all outcome measures 1 year after surgery compared to pre-operatively. 
Table 10. Pre- and post-operative $3 D$ movements in rotation and translation for each patient. $L E=$ laminectomy. $L T=$ bilateral laminotomies. (Paper IV)

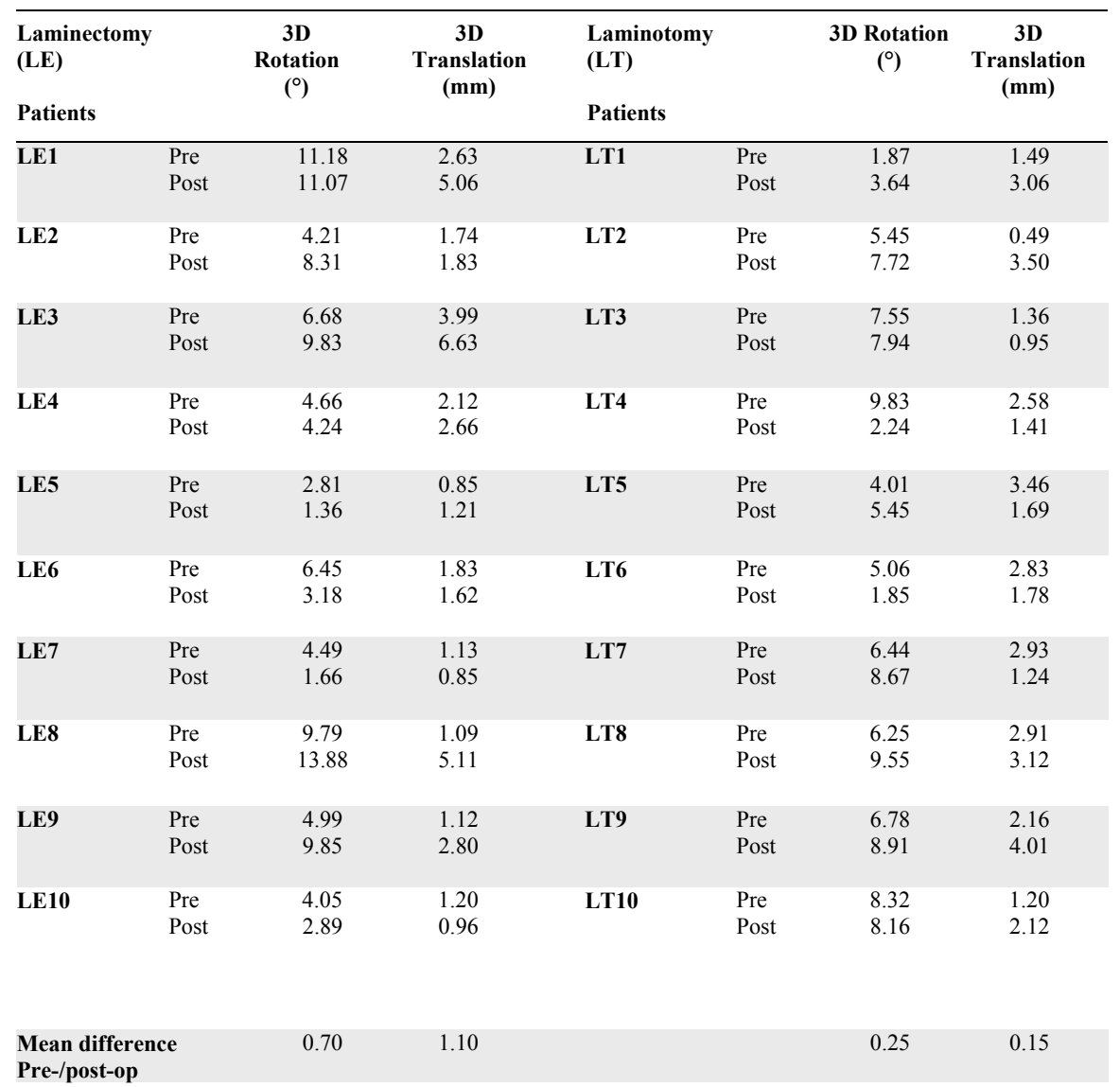

Table 11. Most important patient-reported outcome measures. Note: The study was not powered to detect differences in clinical outcome. Hence, no conclusions can be made regarding differences between laminectomy (LE) and bilateral laminotomies (LT). (Paper IV)

\begin{tabular}{l|lll} 
Outcome measure & Pre-op & 1-year post-op & \\
\hline ODI & 38 & 15 & $P<0.001$ \\
EQ-5D & 0.46 & 0.82 & $P<0.001$ \\
Back pain VAS & 45 & 14 & $P<0.001$ \\
Leg pain VAS & 63 & 23 & $P<0.001$
\end{tabular}




\section{General discussion}

An ageing population will continue to place great strain on healthcare resources across the globe. Because LSS is a condition affecting this elderly population and because surgery for this diagnosis is the most common spinal procedure, the diagnosis will continue to receive increasing attention in the coming decades. All studies performed within the frame of this thesis show a better situation for the patients at a 1-2 year follow-up after surgery for LSS compared with their situation before surgery. Lower levels of pain, improvements in QoL, daily function and walking ability and the superior results from surgery compared with non-surgical treatments have been repeatedly validated in several studies. ${ }^{17-20,79}$ The yearly loss of walking ability in elderly normal ageing has been reported to be substantial (i.e. 1.6\%). ${ }^{80}$ The walking test performed in the Swedish spinal stenosis study (Paper III) revealed a significant improvement in walking capacity. This improvement occurred despite that the patients were 2 years older at the time of the follow-up. The mean improvement of 80 meters after 2 years is well above the minimally clinical relevant difference (MCID) of 18 meters $^{81}$ and is thus a notable benefit for the patients. When comparing surgeries, we found no benefit of fusion as an adjunct to decompression. This observation was noted whether degenerative spondylolisthesis (DS) was present pre-operatively or not. Apart from not being beneficial for the patient, fusion as a complement to decompression was found not to be cost-effective. Nor did we find indications of an increased instability with a traditional and safe method for decompression in patients with DS using laminectomy (LE) compared with a more demanding technique (i.e. bilateral laminotomies, LT) that preserves the segmental midline structures.

\section{Effect of smoking on surgical results}

In Paper I, smokers, in comparison with non-smokers, demonstrated poorer results after surgery for LSS. Non-smokers, on the other hand, exhibited better walking ability, less back and leg pain, higher satisfaction with surgery, higher probability of returning to work, lower consumption of analgesics, and higher QoL 2 years after surgery. Before surgery, smokers had slightly more pain and a somewhat lower QoL and function as measured with the EQ-5D, ODI and SF-36. Smokers are known to demonstrate inferior 
baseline scores in general outcome measures. In addition, in spine patients, medical and psychosocial co-morbidities (such as smoking) negatively impact baseline functional scores such as ODI and SF- $36{ }^{82}$

Several explanations can be proposed for the poorer surgical results in smokers and the mechanism underlying the association between smoking and low back pain. Smoking, for instance, decreases blood flow to the vertebral bodies, which leads to decreased metabolism of the intervertebral discs and an increased degeneration of the discs. ${ }^{83-85}$ The increased coughing that is caused by smoking increases intra-abdominal and lumbar intradiscal pressure, conditions that could lead to bulging or herniation of the intervertebral discs, which is one of the components of spinal stenosis. ${ }^{86}$ Smoking is associated with decreased bone mineral density (BMD) and osteoporosis that may eventually cause back pain. ${ }^{87-90}$ Moreover, smoking increases the blood levels of pro-inflammatory cytokines known to be important mediators of pain in the central nervous system. ${ }^{91,92}$ However, there are also suggestions of an analgesic effect from nicotine contributing to the very complex influence of smoking on the pain modulating system. ${ }^{93,94,} 95$ Even in nonsurgically treated older patients with back problems, poorer results from training and traditional rehabilitation have been reported in smokers compared with non-smokers. ${ }^{96}$

Studies that have examined the association between smoking and results after surgery for LSS have not succeeded in demonstrating unequivocal differences between smokers and non-smokers, possibly because of the small sample sizes in these studies. In several studies, there appeared to be a tendency toward poorer results for smokers, but this difference was not statistically significant. ${ }^{18,50,97-100}$

Although the surgical results were inferior for smokers in our study, it should be emphasised that even the smokers experienced considerable pain reduction and improvement in their QoL and walking ability after decompressive surgery. Consequently, our study should not be used as an argument to encourage smokers not to undergo surgery for spinal stenosis on an individual level. On the contrary, our study confirms the importance of preoperative smoking intervention. Effective smoking intervention programmes 4-8 weeks before surgery have been found to reduce the number of complications and secondary surgery, and thus it seems most likely that these beneficial short-term effects will lead to more satisfactory results in the long-term as well. ${ }^{56,101}$

\section{To fuse or not to fuse in decompressive surgery}

The observational cohort study (Paper II) on 5390 patients from the Swespine Register did not show improved results for the 1131 patients treated with decompression with concomitant fusion (i.e. DF) as compared 
with the 4259 patients who had decompression alone (i.e. D). Nor was fusion of any benefit for the 1306 patients with pre-operative DS. These results were later confirmed in the RCT - "The Swedish Spinal Stenosis Study" (Paper III) on 233 patients. Even among the 135 patients who had preoperative DS, there were no benefits from fusion. To evaluate whether there could still be an effect from fusion in those cases with the most pronounced degree of DS, an analysis on a subgroup of 69 DS patients with slip more than the median in the DS group (i.e. $>7.4 \mathrm{~mm}$ ) was performed. However, this analysis showed there were no differences in outcome.

The hypothesis that patients with LSS might suffer from instability after decompression has been suggested by several authors. ${ }^{30,31,33,102}$ This way of thinking has led many spine surgeons to conclude that fusion is beneficial when decompression is performed. The presence of pre-operative DS has often been associated with "instability", a term that today is not clearly defined and explained. From the literature, there is only weak support for the widespread use of fusion in decompressive surgery for LSS, regardless of whether DS is present pre-operatively or not. ${ }^{41,42}$

Concerning LSS without pre-operative signs of potential instability (i.e. DS), the literature comparing D with DF is scarce. In a study by Grob, 45 patients were randomly selected to D or DF. ${ }^{103}$ After a mean follow-up of 28 months, no differences in outcome between the groups were detected. ${ }^{103}$ This absence of any differences was also found in a meta-analysis by Niggemeyer in 1668 patients with a mean follow-up of 4.7 years. ${ }^{104}$ Several observational studies have compared D against DF on a variety of patients with and without pre-operative DS. For instance, a retrospective study by Postacchini on 40 patients concluded that fusion gave better results, in part because of reduced bone regrowth and restenosis than after decompression without fusion 8 years post-surgery. ${ }^{102}$ In a prospective study that included 124 patients and a mean follow-up of 5.8 years, the authors reported a better outcome after fusion. ${ }^{31}$ However, no differences between the two treatment groups could be detected in prospective follow-up studies of 8 and 2 years by Rompe ${ }^{105}$ ( $\mathrm{n}=117$ patients) and Katz ${ }^{106}(\mathrm{n}=272$ patients), respectively. In a prospective study on 285 patients from the Swespine Register Jansson showed no differences in HRQoL (EuroQol) 1 year after surgery. ${ }^{50}$ Cornefjord ${ }^{107}$ performed a retrospective study on 96 patients with a mean followup of 7.1 years (range 4-12 years). The author reported no differences in outcome between the patients who had D and those who had DF. ${ }^{107}$

In recent observational cohort studies from two large spinal surgery registers (Spine Tango and Swespine), no substantial benefit from fusion was demonstrated. ${ }^{108,109}$ In the work by Munting from the Spine Tango Register, outcomes from 1176 decompressive surgeries on LSS patients with a mixture of patients with and without DS (grade 0-1) were evaluated. ${ }^{108}$ The 108 patients who had fusion in combination with decompression scored better at follow-up but had a higher prevalence of surgical and general complications. 
These findings led the author to conclude that none of the studied treatments were superior to one another and that caution should be exercised for the use of fusion ${ }^{108}$. In a study by Sigmundsson on 9051 patients without DS from the Swespine register, no benefit from fusion could be demonstrated 2 years after surgery. ${ }^{109}$

\section{Degenerative spondylolisthesis (DS).}

Some studies have indicated a risk of iatrogenic slip or some increase in the degree of DS after decompression. ${ }^{30,31}$ However, the possible clinical consequences of both a slipped vertebra and "instability" have been under debate for decades. ${ }^{30,32}$ For example, the natural course of untreated DS has been reported to be benign and without being correlated to either progression of slip or clinical symptoms. ${ }^{43}$ Despite this, the use of fusion in LSS patients with DS has been considered as mandatory by the majority of surgeons in order to avoid possible post-operative increased instability and restenosis. In the USA $96 \%$ of patients with DS are operated with a fusion as an adjunct to decompression. ${ }^{36}$ The works by Herkowitz and Kurz ${ }^{33}$ from 1991 and Bridwell et $\mathrm{al}^{34}$ from 1993 have been the main basis for this routine. However, although these studies have been reported as RCTs and thereby with a high degree of evidence, their status as such has been questioned because of the overall design and lack of validated outcome measures. ${ }^{41,110,111}$. Studies of observational design that promote fusion have also had limited validity because of flawed data reporting and small groups of patients. ${ }^{110,112,113}$ In an observational study of 213 patients from the Spine Tango Register, Kleinstueck reported better results when fusion was added to decompression in LSS with DS. ${ }^{114}$ The author compared D with DF in relation to reduction of back and leg pain. The reduction of back pain was greater after fusion, but because the fused patients had more back pain pre-operatively, the level of back pain was equal in the two treatment groups at a 1-year follow-up. ${ }^{114}$ Sigmundsson recently published an observational study from Swespine on 1624 LSS patients with DS. ${ }^{115}$ After 1 year, there was superior result from DF compared to D. However, even though the difference was significant, it was modest and considered not to reach minimal clinical significance. After 2 years, the difference had disappeared between the groups. ${ }^{115}$ In a Canadian study using an observational design, no benefits from fusion were observed in 179 patients with DS. ${ }^{116}$ Despite the weak evidence, DS has been regarded as such a strong indication for fusion that it was an exclusion criterion in a RCT on non-surgical treatment of LSS with epidural steroid injections. ${ }^{23}$

There has been the widespread use of fusion in combination with decompression in LSS patients who, in addition to pseudoclaudicatio (the main reason for decompressive surgery), suffer from notable back pain. In our studies, improvement of back pain was at the same level as the improvement 
of leg pain with or without fusion. This finding held regardless of whether DS was present or not pre-operatively. Furthermore, pre-operative DS was not associated with a higher level of back pain at baseline, a finding also reported in other studies. ${ }^{32,117}$ Our conclusion regarding the importance of pre-operative DS is that it appears to be overestimated.

\section{Complications}

Complications of surgical treatment are difficult to evaluate, possibly because of the large differences in the way that complications are reported in the literature. ${ }^{111}$ In paper II, an evaluation of surgical and post-operative complications was not performed because registration of complications in Swespine has been evaluated with considerable under-reporting and misidentification. ${ }^{118}$

In paper III, we reported on surgical complications as durotomy in $11 \%$ of the operations, regardless of whether decompression was supplemented with fusion or not. More patients in the DF group (10\%) were treated with antibiotics for post-operative wound infections than in the D group (4\%). Documented severe adverse events were few in the present study. However, the multicentre design of the RCT might contribute to underreporting of complications. In addition, the definition on when to treat a suspected wound infection with antibiotics or how to classify other adverse events varies among surgeons. Further, because the study population was not powered to detect differences in complication rates, we were reluctant to draw conclusions on differences in complication rates between the two treatments. Nevertheless, and importantly, several studies indicate that fusion in this elderly population is associated with a higher prevalence of complications than decompression alone. In a study by Deyo on 32152 patients with Medicare claims after surgery for LSS, the OR of having a life threatening complication was 2.6 after simple fusion compared with decompression alone. ${ }^{13}$ Further, the risk of rehospitalisation because of complications within 30 days increased more after fusion compared than after decompression (OR 1.9). ${ }^{13}$ In a more recent study on 12154 LSS patients, major medical complications occurred in $2.1 \%$, wound complications in $3.2 \%$ and 90 -day mortality in $0.6 \%$. In the same study, a higher rate of medical complications was found for DF compared with D (OR 2.85). ${ }^{119}$ The study by Munting from the Spine Tango Register also revealed higher proportions of both surgical and general complications after DF compared with D. ${ }^{108}$

\section{Re-operations}

Re-operation or repeated lumbar surgery after operations for LSS is not welldefined and seldom described in the literature. LSS is caused by normal degenerative changes that to some extent are present and progress on a number 
of spinal segments in older persons. This fact makes it difficult to determine whether a subsequent operation after an earlier index operation is a consequence of a suboptimal technique or performance at the primary intervention or an effect of normal ageing.

In the Swedish spinal stenosis study (Paper III), $11 \%$ of the patients in the D group and $15 \%$ of the patients in the DF group had subsequent lumbar surgery within the 2-year follow-up period. The reason for a second surgery in the DF group was merely revisions due to infection, and above all, a new stenotic segment adjacent to the fusion. The risk of having accelerated degenerative changes adjacent to a lumbar fusion is well known. ${ }^{38}$ This risk has been pointed out to be particularly relevant for older patients and for patients operated on for LSS. ${ }^{39,40}$ Repeated surgery in the D group was necessary because of revisions due to infections, severe back pain and adjacent level stenosis but mostly related to the progression of degeneration in operated segments with recurrence of neural compression.

Despite our relatively broad definition of a re-operation in Paper II, the frequency of repeated surgery was lower than in other studies: $7 \%$ of the patients in the D group and $8 \%$ of the patients in the DF group had subsequent surgery up to 11 years after the index operation. We included from the Swespine register not only a second operation on the level previously operated but also any later operation in the lumbar spine with decompression or fusion for spinal stenosis or post-operative instability.

The definition of re-operation is not very clear among surgeons in general, and particularly among Swedish spine surgeons, who register this in Swespine. Hence, the data in the register pertaining to repeated surgery are difficult to evaluate.

The incidence of repeated surgery in LSS patients reported in the literature varies considerably. A register study of 5699 patients operated for LSS showed an 11-year cumulative re-operation frequency of $17 \%$ after D and $20 \%$ after $\mathrm{DF}^{110}$. There was a $32 \%$ greater likelihood of having a reoperation after the first year post-operatively following fusion compared with decompression alone. ${ }^{110}$ In a Swedish study on 9664 patients from the Swedish National Inpatient Register, a re-operation frequency of $11 \%$ was found with a slightly, though not significantly, lowered risk when fusion was performed. ${ }^{120}$ In other studies on smaller populations of patients, the frequency of re-operations varied from 5-24\%. ${ }^{121-124}$

\section{Health economic considerations}

In the large multicentre RCT (Paper III), D achieved the same clinical effect as DF. The latter, however, significantly increased direct costs (hospital costs), including surgery and inpatient stay. Fusion as a complement to decompression was found not to be cost-effective. Each DF was 56000 SEK ( $\sim 6800$ USD) more expensive than D. In the literature, there are scarce data 
on health economic evaluations on LSS surgery. In a study by Tosteson from the Spine Patient Outcomes Research Trial (SPORT), there was no difference (with or without DS) between D and DF in QALY (qualityadjusted life year) ${ }^{125}$. In their study, the total treatment cost per patient for DF was 20967 USD more expensive than D in the group without DS and 17545 USD more costly with DS but without better clinical outcome. ${ }^{125,126}$ Our results indicate that limiting the fusion rate could substantially reduce costs without sacrificing quality. Apart from the lower treatment cost for each patient, the use of decompression without fusion can also save resources by releasing capacity in the operation theatre and the post-operative ward through shorter surgery time and hospital stay. This would be of particular benefit in a community with over-stretched public medical services that produce long queues for medical treatment.

\section{Decompression and instability}

As mentioned earlier, the term "instability" is vague or has not been clearly defined. It is a daily dilemma for spine surgeons to evaluate both preoperative stability and the risk of creating an unstable situation from surgery. In our biomechanical pilot study (Paper IV) on patients operated on for LSS, we found a minimal increase in movement at provocation in extension and flexion 6 months after decompressive surgery (without fusion). For the study group, we selected a population with a condition that by many surgeons is regarded as unstable already before surgery, i.e. with pre-operative DS. However, removal of the midline structures did not lead to significantly increased instability when compared with preserved structures. Although the study was underpowered to draw any conclusions of differences in clinical results between the removal and preservation of the midline structures, there was significant improvement from pre-operative levels in all studied patientreported outcome measures 1year after surgery.

These results do not support previous studies showing that instability increased according to the extent of removal of intersegmental structures, especially for the interspinal processes and ligaments. ${ }^{29,}{ }^{127}$ In a study on cadaver segments, even minimal invasive decompression with preserved interspinous ligaments significantly reduced the stiffness of those segments that underwent surgery. ${ }^{29}$ In a biochemical study using a porcine model, removal of the interspinous ligaments caused more instability after decompression than preservation of the ligaments. ${ }^{127}$ In a retrospective study, hypermobility in sagittal rotation (flexion/extension) was associated with poor outcome after decompression. ${ }^{128}$ However, in another biomechanical study on spinal segments from human cadavers, decompression, including medial facetectomy and resection of interspinous ligaments, did not affect lumbar stability. ${ }^{28}$ 
In a randomised comparison of unilateral laminotomy, bilateral laminotomy and laminectomy Thomé found superior clinical outcome after midline preserving techniques. ${ }^{129}$ However, in a recent register study from Norway on 885 patients, no differences could be found between microdecompressive surgery with preservation of the midline structures compared to laminectomy. ${ }^{130}$ This was also the conclusion reached in a recent Cochrane review on the effectiveness of posterior decompression techniques compared with conventional LE. ${ }^{131}$ In summary, the review found low or very low evidence for the superior effect of unilateral laminotomy for bilateral decompression, bilateral laminotomy and split-spinous process laminotomy compared with conventional laminectomy. No advantages for the microdecompressive techniques were found for complications, length of the procedure, length of hospital stay or post-operative walking ability when compared with laminectomy. ${ }^{131}$

A possible explanation of the preserved segmental stability in our study (Paper IV), despite decompression with removal of stabilising structures, is that it is a biomechanical study in vivo that allows remaining interspinal structures and (with time) scarring tissue to play a stabilising role. Many of the above-mentioned biomechanical studies were done in vitro on lumbar segments from cadavers.

The CT method used in our study (Paper IV) for measuring 3D movements in rotation and translation proved to be useful and easy to perform, even in a group of elderly patients. This technique for measuring spinal movements has been shown to be safe and reliable with an accuracy of 0.6 $\mathrm{mm}$ (accuracy for conventional x-ray is $4 \mathrm{~mm}$ ). ${ }^{75,132,133}$ The method is only surpassed by RSA (Radio Stereometric Analysis), which has an accuracy of $0.2 \mathrm{~mm}$. RSA, though, has the disadvantage of being an invasive procedure. ${ }^{134-136}$

We used a low-dose CT protocol with a calculated dose exposure of 1.4 $\mathrm{mS}$. For comparison, a lateral lumbar X-ray exposes a patient to approximately 0.3-0.4 mS. However, most lumbar X-ray investigations include four pictures (two lateral and two anterior-posterior views) that when added up are nearly equivalent to the exposure of a low-dose CT scan. In the future, with the advent of new CT hardware and software, radiation exposure will likely be decreased further while maintaining or increasing precision.

Thus, in our pilot study (Paper IV), the midline structures did not play an important role in the stability of a lumbar segment. This finding supports the hypothesis that decompression for LSS with DS can be done safely with laminectomy. The 3DCT technique for evaluation of spinal movements and stability is a safe and simple method that has the potential to be an important tool in biomechanical studies. 


\section{Strengths and limitations}

The major strengths of our research are its use of a large national register with prospectively collected data, well-defined patient populations and the use of well-documented and validated outcome measures as well as established statistical methods. For the RCT (The Swedish spinal stenosis study, Paper III), the randomisation process resulted in establishing treatment groups with no differences at baseline, which allows a direct and confident comparison of results at follow-up. A major limitation of the observational design used in Paper I and II is the selection bias that arises from such designs.

The biomechanical pilot study (Paper IV) was underpowered to make clear conclusions from the results. However, it serves as an indicator of the minimal impact decompressive surgery have on stability in lumbar segments and serves as an encouragement to include more patients in future studies.

Loss to follow-up is always a limitation in clinical studies. In our two observational studies, $36 \%$ of the patients in Paper I and 34\% in Paper II did not have data on outcome or data were lacking on smoking habits. Although these figures are quite high, the pre-operative characteristics and the proportions of smokers/non-smokers (Paper I) and the two surgical methods (Paper II) among patients lost to follow-up did not differ from the studied groups. Solberg et al ${ }^{136}$ evaluated the outcome in patients lost to follow-up in a prospective study of patients who underwent surgery for degenerative lumbar disorders. The authors found that non-responders had the same result as responders. Thus, we can assume that loss to follow-up did not affect the conclusions of the present studies. A strength in the RCT study (Paper III) was that only five patients (2\%) were lost to follow-up. In Paper IV (a randomised pilot study), we had three patients (13\%) that had to be excluded after inclusion because of technical or surgical issues but all the remaining patients were present at follow-up.

In the RCT (Paper III) study, we used the Swespine Register to collect patient-reported data/results. The use of registers in RCTs greatly simplifies trials by providing a structured logistics for data collection. After patients were randomly assigned to one of the two procedures, they were followed according to normal procedures in the register. This use of registers has been proven to be of value in large RCTs. ${ }^{137}$

Validated and reliable radiological methods to diagnose instability are lacking. In the RCT (Paper III) study, we used conventional lateral X-ray as 
a complement to MRI pre-operatively to establish the diagnosis of LSS as well as to look for indications of DS. In the literature, flexion/extension Xray is frequently used to diagnose instability in the form of DS. This method, however, is associated with a wide range of measurement errors (up to 4 $\mathrm{mm}$ ) and there is no general agreement on a normal pattern or range of sagittal plane movements in the lumbar spines of healthy subjects. ${ }^{138}$ It also depends on patients' pain status and co-operation. Finally, the method has low repeatability. ${ }^{139}$ In the award winning biomechanical study by Shaffer et al., from 1990 it was concluded that flexion/extension X-ray for diagnosing instability can lead to serious errors in classification unless the observed translation exceeds $5 \mathrm{~mm} .{ }^{132}$ In our RCT (Paper III), an analysis on the subgroup of DS patients with the most pronounced slip $(7.4-14.3 \mathrm{~mm})$ revealed no differences in outcome compared with all DS patients or the patients without DS. Such a finding gives us confidence that our diagnostic method is not a bias. However, the 3DCT technique with a validated high accuracy used in Paper IV is a strength. 


\section{Conclusions}

Surgical results for lumbar spinal stenosis (LSS) in smokers were inferior compared with those in non-smokers for all studied outcome measures 2 years post-surgery.

At the 2-year follow-up, fusion as a compliment to decompression did not lead to better clinical results than decompression alone. This finding held whether degenerative spondylolisthesis (DS) was present or not prior to surgery.

Decompression with concomitant fusion led to more bleeding, longer operating time, longer hospital stay and higher operation costs than decompression alone. Thus, fusion as a compliment to decompression is neither cost effective or in any other way beneficial for these elderly patients, in a two year timeframe.

In our biomechanical pilot study decompression of LSS with DS caused a minimal increase in instability measured after 6 months with 3DCT. Resection of the midline structures with laminectomy did not lead to increased instability compared with preserving these structures with bilateral laminotomies. 


\section{Further research}

Further efforts should be made to identify which patients benefit most from surgery for LSS. Actions should also be made to seek predictors for inferior outcome and thus knowledge on which patients benefit most from continued non-operative treatment.

In the Swedish Spinal Stenosis Study (SSSS), which was the base for the clinical results reported in Paper III, a radiologic evaluation was done. CT was performed directly after surgery and repeated at the 2-year follow-up. MRI and standard X-ray were carried out before surgery and also repeated at the 2-year follow-up. The evaluation of these modalities is underway and will hopefully lead to a better understanding of the progression of degenerative changes in operated and adjacent segments. The aim of this analysis is to find radiological predictors of further degeneration and iatrogenic instability that can be correlated to the clinical outcome. This will lead to more validated decision-making in the choice of surgical treatment for individual patients. The clinical results from SSSS will be evaluated with longer followup of 5 and 10 years through the logistics of the Swespine register

To further consolidate the results from the biomechanical pilot study (Paper IV), on the choice of technique to perform a decompression, more patients should be included and followed over a longer time with 3DCT. 


\section{Summary in Swedish}

\section{Kirurgi för spinal stenos i ländryggen.}

Lumbal spinal stenos (LSS) är ett tillstånd som karakteriseras av smärta i rygg och ben samt inskränkt gångförmåga och en känsla av domningar och svaghet $\mathrm{i}$ benen. Orsaken är degenerativa förändringar i leder, diskar och ledband mellan kotorna i ländryggen vilket ger en trängsel i ryggradskanalen med påverkan på nervstrukturer som följd. LSS drabbar företrädesvis äldre personer och är ovanligt hos personer yngre än 50 år.

Prevalensen av kirurgi för LSS har ökat kraftigt som ett uttryck för en ökad medvetenhet om tillståndet, förbättrad diagnostik och framför allt en förskjutning av ålderspyramiden med större andel äldre, som har allt högre krav på fortsatt aktivitet och välmående. LSS är sedan några år tillbaka den vanligaste anledningen till att genomgå ryggkirurgi i Sverige och utgör drygt hälften av alla operationsfall i ländryggen. Varje år opereras ca 5000 patienter i Sverige för denna diagnos och operationsfrekvensen har de senaste åren ökat med 5-10\% årligen. Flera studier har pekat på ett bättre resultat av kirurgisk behandling jämfört med icke operativ handläggning. Målet med kirurgin är att avlasta nervstrukturerna $i$ spinalkanalen genom att avlägsna delar av de degenerativa förändringar i leder, ledband och disk som ger trängseln, s.k. dekompression (D).

Många ryggkirurger har ansett att dekompressionen riskerar att leda till en instabilitet mellan de opererade kotorna med ett dåligt resultat för patienten som följd. Därför har det varit vanligt att komplettera dekompressionen med en samtidig fusion (steloperation) för att stabilisera segmentet (DF). Detta har varit särskilt vanligt vid pre-operativ förekomst av glidning mellan kotorna (s.k. degenerativ spondylolistes, DS). Fusion som tillägg till dekompressionen (DF) innebär dock en ökad risk för komplikationer och är mer resurskrävande än enbart dekompression (D). Dekompression av nervstrukturerna i ryggradskanalen kan göras på huvudsakligen två sätt. Antingen centralt då strukturerna $\mathrm{i}$ medellinjen mellan kotorna avlägsnas eller med separat åtkomst på bägge sidor om strukturerna i medellinjen så att dessa bevaras. Den senare tekniken är mer tekniskt krävande och behäftad med större risk för komplikationer med skador på nervstrukturer. Rökning har negativa effekter på anatomiska strukturer i ryggen som diskar, leder och 
skelett och det är känt att rökare har en ökad risk att utveckla ryggbesvär jämfört med ickerökare. Det är också känt att rökning innebär en ökad risk för komplikationer vid all slags kirurgi.

Det övergripande målet med denna avhandling har varit att utvärdera vilken kirurgisk metod för LSS som ger ett gott resultat med minskad smärta och ökad funktion men med lägst risk för komplikationer och oönskade händelser. Detta till lägst kostnad och bäst resursutnyttjande. Målet har också varit att utvärdera om det är en skillnad i resultat av kirurgin mellan rökare och ickerökare.

Det nationella kvalitetsregistret för ryggkirurgi (Swespine) användes för att samla in data kring resultat av operation för LSS. Två stora patientgrupper följdes prospektivt med uppföljning 2 år efter kirurgin. Data bearbetades med multivariat analys för 4555 patienter med avseende på effekten av rökning för det kirurgiska resultatet (Studie I) och för 5390 patienter avseende skillnad i resultat mellan dekompression med samtidig fusion och enbart dekompression (Studie II). I den randomiserade kontrollerade studien, Svenska Spinal Stenos Studien, fördelades 233 patienter slumpmässigt mellan operation med dekompression med samtidig fusion och enbart dekompression (Studie III) och följdes i två år. Det gjordes även en analys av alla direkta och indirekta kostnader för samhälle och patient förknippade med respektive operation och efterföljande behandlingar under uppföljningstiden 2 år. I både Studie II och III gjordes en underanalys för de patienter som hade preoperativ förekomst av kotglidning, DS. I en radiologisk pilotstudie (Studie IV) användes tredimensionell segmentell rörelseanalys med datortomografi (3DCT) för att utvärdera medellinjestrukturernas stabiliserande roll i det opererade segmentet med spinal stenos (LSS) och samtidig kotglidning (DS). 23 patienter randomiserades mellan central dekompression, s.k. laminektomi, då kotbåge, taggutskott och ledband i medellinjen avlägsnas och bilaterala s.k. laminotomier då dessa strukturer bevaras.

Rökare visade sig ha ett sämre resultat av kirurgin jämfört med icke-rökare. Detta gällde såväl smärta, allmän funktion och gångförmåga där rökarna hade en lägre grad av förbättring jämfört med icke-rökarna.

Dekompression med samtidig fusion gav inte ett bättre resultat än enbart dekompression. Detta oavsett om kotglidning (DS) förekom preoperativt eller inte. Dekompression med samtidig fusion visade sig innebära klart högre kostnader för samhället och var inte kostnadseffektivt jämfört med enbart dekompression. 
Den ökade rörlighet som uppstår i ett lumbalt segment efter dekompression var minimal och det gav ingen skillnad om medellinjestrukturerna avlägsnats eller inte.

Konklusioner från avhandlingen:

- Dekompression utan samtidig fusion bör generellt sett vara förstahandsval vid kirurgisk behandling av LSS oavsett ev. förekomst av preoperativ kotglidning (DS).

- Insatser för rökstopp bör göras hos rökare inför kirurgi för LSS för att förbättra resultaten och minska risken för komplikationer.

- Dekompression för LSS kan göras centralt med avlägsnande av medellinjestrukturerna med större säkerhet och utan ökad risk för instabilitet jämfört med om dessa strukturer bevaras. 


\section{Acknowledgements}

I would like to express my sincere gratitude to all those who have directly or indirectly contributed to the completion of this work, and especially to:

Bengt Sandén, my head supervisor, for all his support, encouragement and the meticulous audits of my work.

Karl Michaëlsson, my co-supervisor, for sharing his great experience in science and for his enthusiastic efforts to guide me through the labyrinths of statistics.

Michael Cornefjord, my original supervisor and friend, who died far too young.

Tycho Tullberg, CEO and founder of Stockholm Spine Center, for all his support and for prioritizing clinical research in an environment with high economic demands.

Catharina Strömstedt, research nurse at the Orthopedic Department, Uppsala University Hospital, for keeping me organized and for her careful managing of our studies.

Eva Gulle and Carola Skärvinge, research nurses at Stockholm Spine Center, for their precision and concern with the logistics of the clinical studies.

Margareta Ekström, Marie Bygdén and Monica Aspén, surgical coordinators, and Lisa Englund, medical secretary, at Stockholm Spine Center for enthusiastically accepting my constantly new ideas and the workload following with study protocols, randomisation processes and follow-up visits in our clinical studies.

The Swedish Lumbar Spine Study group, initiators of the Swedish Spinal Stenosis Study.

Gylfi Ólafsson, Per Svedmark, Thomas Carlsson, Patrik Öhagen, Anders Frost, Fredrik Borgström, Peter Fritzell and Marilyne Noz, co-authors, for fruitful collaboration and professional discussions. 
Peter Öhman and Andreas Söderholm, IT gurus at Datatrion, for excellent support in the creation of this thesis.

Maja Dahlqvist and Ebba Bergman, Uppsala Clinical Research Center for valuable help with the structure and layout of Paper III.

Leslie Shaps, for prompt and professional proofreading.

Friends and former colleagues in the Spine Section and the Orthopedic Department at Uppsala University Hospital for many years of captivating discussions and immeasurable pleasure.

All co-workers at Stockholm Spine Center for unwavering support and for making it joyful to go to work every day.

Michael Försth, my little brother. Professor and $\mathrm{PhD}$ of technology, for his support with statistical understanding and for calculating confidence intervals manually when I did not have a healthy relationship to statistical software. But mostly for always being a great support in the ups and downs of life.

Gunnel and Lasse Försth, my parents, for always being there for me with love, encouragement and support.

My lovely daughters, Agnes, Saga and Lisa, simply for being the best there is. 


\section{References}

1. Katz JN, Dalgas M, Stucki G, et al. Degenerative lumbar spinal stenosis. Diagnostic value of the history and physical examination. Arthritis Rheum 1995;38:1236-41.

2. Watters WC, 3rd, Baisden J, Gilbert TJ, et al. Degenerative lumbar spinal stenosis: an evidence-based clinical guideline for the diagnosis and treatment of degenerative lumbar spinal stenosis. Spine J 2008;8:305-10.

3. Hansson T, Suzuki N, Hebelka H, Gaulitz A. The narrowing of the lumbar spinal canal during loaded MRI: the effects of the disc and ligamentum flavum. Eur Spine J 2009;18:679-86.

4. Newman PH. Spondylolisthesis, its cause and effect. Ann R Coll Surg Engl 1955;16:305-23.

5. Kirkaldy-Willis WH, McIvor GW. Editorial: Lumbar spinal stenosis. Clin Orthop Relat Res 1976:2-3.

6. Schonstrom N, Lindahl S, Willen J, Hansson T. Dynamic changes in the dimensions of the lumbar spinal canal: an experimental study in vitro. J Orthop Res 1989;7:115-21.

7. Barz T, Melloh M, Staub LP, et al. Nerve root sedimentation sign: evaluation of a new radiological sign in lumbar spinal stenosis. Spine (Phila $\mathrm{Pa}$ 1976);35:892-7.

8. Schizas C, Theumann N, Burn A, et al. Qualitative grading of severity of lumbar spinal stenosis based on the morphology of the dural sac on magnetic resonance images. Spine (Phila Pa 1976);35:1919-24.

9. Swespine annual reports, www.4s.nu

10. Lurie JD, Tosteson TD, Tosteson A, et al. Long-term outcomes of lumbar spinal stenosis: eight-year results of the Spine Patient Outcomes Research Trial (SPORT). Spine (Phila Pa 1976);40:63-76.

11. Stromqvist B, Fritzell P, Hagg O, Jonsson B. The Swedish Spine Register: development, design and utility. Eur Spine J 2009;18 Suppl 3:294-304.

12. Ciol MA, Deyo RA, Howell E, Kreif S. An assessment of surgery for spinal stenosis: time trends, geographic variations, complications, and reoperations. J Am Geriatr Soc 1996;44:285-90.

13. Deyo RA, Mirza SK, Martin BI, Kreuter W, Goodman DC, Jarvik JG. Trends, major medical complications, and charges associated with surgery for lumbar spinal stenosis in older adults. JAMA;303:1259-65.

14. Du Bois M, Szpalski M, Donceel P. A decade's experience in lumbar spine surgery in Belgium: sickness fund beneficiaries, 2000-2009. Eur Spine $\mathrm{J} ; 21: 2693-703$.

15. United Nations, Department of Economic and Social Affairs, Population Division (2013).World Population Ageing 2013. ST/ESA/SER.A/348

16. Deyo RA. Treatment of lumbar spinal stenosis: a balancing act. Spine $\mathrm{J} ; 10: 625-7$. 
17. Atlas SJ, Keller RB, Robson D, Deyo RA, Singer DE. Surgical and nonsurgical management of lumbar spinal stenosis: four-year outcomes from the maine lumbar spine study. Spine (Phila Pa 1976) 2000;25:556-62.

18. Amundsen T, Weber H, Nordal HJ, Magnaes B, Abdelnoor M, Lilleas F. Lumbar spinal stenosis: conservative or surgical management?: A prospective 10-year study. Spine (Phila Pa 1976) 2000;25:1424-35; discussion 35-6.

19. Malmivaara A, Slatis P, Heliovaara M, et al. Surgical or nonoperative treatment for lumbar spinal stenosis? A randomized controlled trial. Spine (Phila $\mathrm{Pa}$ 1976) 2007;32:1-8.

20. Weinstein JN, Lurie JD, Tosteson TD, et al. Surgical versus nonoperative treatment for lumbar disc herniation: four-year results for the Spine Patient Outcomes Research Trial (SPORT). Spine (Phila Pa 1976) 2008;33:2789-800.

21. Kovacs FM, Urrutia G, Alarcon JD. Surgery versus conservative treatment for symptomatic lumbar spinal stenosis: a systematic review of randomized controlled trials. Spine (Phila Pa 1976);36:E1335-51.

22. Porter RW. Spinal stenosis and neurogenic claudication. Spine (Phila Pa 1976) 1996;21:2046-52.

23. Friedly JL, Comstock BA, Turner JA, et al. A randomized trial of epidural glucocorticoid injections for spinal stenosis. N Engl J Med;371:11-21.

24. Nord T, Kornerup U, Gronlund P, Reuterwall C. [In Process Citation]. Lakartidningen; 112 .

25. Postacchini F, Cinotti G, Perugia D, Gumina S. The surgical treatment of central lumbar stenosis. Multiple laminotomy compared with total laminectomy. J Bone Joint Surg Br 1993;75:386-92.

26. Cleveland M, Bosworth DM, Thompson FR. Pseudarthrosis in the lumbosacral spine. J Bone Joint Surg Am 1948;30A:302-12.

27. Roy-Camille R, Roy-Camille M, Demeulenaere C. [Osteosynthesis of dorsal, lumbar, and lumbosacral spine with metallic plates screwed into vertebral pedicles and articular apophyses]. Presse Med 1970;78:1447-8.

28. Abumi K, Panjabi MM, Kramer KM, Duranceau J, Oxland T, Crisco JJ. Biomechanical evaluation of lumbar spinal stability after graded facetectomies. Spine (Phila Pa 1976) 1990;15:1142-7.

29. Hamasaki T, Tanaka N, Kim J, Okada M, Ochi M, Hutton WC. Biomechanical assessment of minimally invasive decompression for lumbar spinal canal stenosis: a cadaver study. Journal of spinal disorders \& techniques 2009;22:486-91.

30. Johnsson KE, Redlund-Johnell I, Uden A, Willner S. Preoperative and postoperative instability in lumbar spinal stenosis. Spine (Phila Pa 1976) 1989;14:591-3.

31. Fox MW, Onofrio BM, Hanssen AD. Clinical outcomes and radiological instability following decompressive lumbar laminectomy for degenerative spinal stenosis: a comparison of patients undergoing concomitant arthrodesis versus decompression alone. J Neurosurg 1996;85:793-802.

32. Hasegawa K, Kitahara K, Shimoda H, et al. Lumbar degenerative spondylolisthesis is not always unstable: clinicobiomechanical evidence. Spine (Phila Pa 1976);39:2127-35.

33. Herkowitz HN, Kurz LT. Degenerative lumbar spondylolisthesis with spinal stenosis. A prospective study comparing decompression with decompression and intertransverse process arthrodesis. J Bone Joint Surg Am 1991;73:802-8.

34. Bridwell KH, Sedgewick TA, O'Brien MF, Lenke LG, Baldus C. The role of fusion and instrumentation in the treatment of degenerative spondylolisthesis with spinal stenosis. J Spinal Disord 1993;6:461-72. 
35. Bae HW, Rajaee SS, Kanim LE. Nationwide trends in the surgical management of lumbar spinal stenosis. Spine (Phila Pa 1976);38:916-26.

36. Kepler CK, Vaccaro AR, Hilibrand AS, et al. National trends in the use of fusion techniques to treat degenerative spondylolisthesis. Spine (Phila $\mathrm{Pa}$ 1976);39:1584-9.

37. Jansson KA, Blomqvist P, Granath F, Nemeth G. Spinal stenosis surgery in Sweden 1987-1999. Eur Spine J 2003;12:535-41.

38. Lehmann TR, Spratt KF, Tozzi JE, et al. Long-term follow-up of lower lumbar fusion patients. Spine (Phila Pa 1976) 1987;12:97-104.

39. Park P, Garton HJ, Gala VC, Hoff JT, McGillicuddy JE. Adjacent segment disease after lumbar or lumbosacral fusion: review of the literature. Spine (Phila Pa 1976) 2004;29:1938-44.

40. Aota Y, Kumano K, Hirabayashi S. Postfusion instability at the adjacent segments after rigid pedicle screw fixation for degenerative lumbar spinal disorders. J Spinal Disord 1995;8:464-73.

41. Vaccaro AR, Garfin SR. Degenerative lumbar spondylolisthesis with spinal stenosis, a prospective study comparing decompression with decompression and intertransverse process arthrodesis: a critical analysis. Spine (Phila Pa 1976) 1997;22:368-9.

42. Eisenstein S. Fusion for spinal stenosis: a personal view. J Bone Joint Surg Br 2002;84:9-10.

43. Matsunaga S, Sakou T, Morizono Y, Masuda A, Demirtas AM. Natural history of degenerative spondylolisthesis. Pathogenesis and natural course of the slippage. Spine (Phila Pa 1976) 1990;15:1204-10.

44. Matsunaga S, Ijiri K, Hayashi K. Nonsurgically managed patients with degenerative spondylolisthesis: a 10- to 18-year follow-up study. J Neurosurg 2000;93:194-8.

45. Moojen WA, Arts MP, Jacobs WC, et al. Interspinous process device versus standard conventional surgical decompression for lumbar spinal stenosis: randomized controlled trial. BMJ;347:f6415.

46. Stromqvist BH, Berg S, Gerdhem P, et al. X-stop versus decompressive surgery for lumbar neurogenic intermittent claudication: randomized controlled trial with 2-year follow-up. Spine (Phila Pa 1976);38:1436-42.

47. Haddad B, Makki D, Konan S, Park D, Khan W, Okafor B. Dynesys dynamic stabilization: less good outcome than lumbar fusion at 4-year follow-up. Acta Orthop Belg;79:97-103.

48. Lee MJ, Lindsey JD, Bransford RJ. Pedicle screw-based posterior dynamic stabilization in the lumbar spine. J Am Acad Orthop Surg;18:581-8.

49. Zanoli G, Jonsson B, Stromqvist B. SF-36 scores in degenerative lumbar spine disorders: analysis of prospective data from 451 patients. Acta Orthop 2006;77:298-306.

50. Jansson KA, Nemeth G, Granath F, Jonsson B, Blomqvist P. Health-related quality of life (EQ-5D) before and one year after surgery for lumbar spinal stenosis. J Bone Joint Surg Br 2009;91:210-6.

51. Stromqvist B, Fritzell P, Hagg O, Jonsson B, Sanden B. Swespine: the Swedish spine register : the 2012 report. Eur Spine J;22:953-74.

52. Hara N, Oka H, Yamazaki T, et al. Predictors of residual symptoms in lower extremities after decompression surgery on lumbar spinal stenosis. Eur Spine $\mathrm{J} ; 19: 1849-54$.

53. Aalto TJ, Malmivaara A, Kovacs F, et al. Preoperative predictors for postoperative clinical outcome in lumbar spinal stenosis: systematic review. Spine (Phila Pa 1976) 2006;31:E648-63. 
54. Katz JN, Stucki G, Lipson SJ, Fossel AH, Grobler LJ, Weinstein JN. Predictors of surgical outcome in degenerative lumbar spinal stenosis. Spine (Phila Pa 1976) 1999;24:2229-33.

55. Jonsson B, Annertz M, Sjoberg C, Stromqvist B. A prospective and consecutive study of surgically treated lumbar spinal stenosis. Part II: Five-year follow-up by an independent observer. Spine (Phila Pa 1976) 1997;22:2938-44.

56. Moller AM, Villebro N, Pedersen T, Tonnesen H. Effect of preoperative smoking intervention on postoperative complications: a randomised clinical trial. Lancet 2002;359:114-7.

57. Moller AM, Pedersen T, Villebro N, Munksgaard A. Effect of smoking on early complications after elective orthopaedic surgery. J Bone Joint Surg Br 2003;85:178-81.

58. Sadr Azodi O, Bellocco R, Eriksson K, Adami J. The impact of tobacco use and body mass index on the length of stay in hospital and the risk of postoperative complications among patients undergoing total hip replacement. J Bone Joint Surg Br 2006;88:1316-20.

59. Videman T, Battie MC, Parent E, Gibbons LE, Vainio P, Kaprio J. Progression and determinants of quantitative magnetic resonance imaging measures of lumbar disc degeneration: a five-year follow-up of adult male monozygotic twins. Spine (Phila Pa 1976) 2008;33:1484-90.

60. Silcox DH, 3rd, Daftari T, Boden SD, Schimandle JH, Hutton WC, Whitesides TE, Jr. The effect of nicotine on spinal fusion. Spine (Phila Pa 1976) 1995;20:1549-53.

61. Fairbank JC, Pynsent PB. The Oswestry Disability Index. Spine (Phila Pa 1976) 2000;25:2940-52; discussion 52.

62. Jenkinson C, Wright L, Coulter A. The SF 36 health survey questionnaire. ...if used within its limits. BMJ 1993;307:449.

63. Brooks R. EuroQol: the current state of play. Health Policy 1996;37:53-72.

64. Zanoli G, Nilsson LT, Stromqvist B. Reliability of the prospective data collection protocol of the Swedish Spine Register: test-retest analysis of 119 patients. Acta Orthop 2006;77:662-9.

65. Stokes IA, Frymoyer JW. Segmental motion and instability. Spine (Phila Pa 1976) 1987;12:688-91.

66. Stucki G, Daltroy L, Liang MH, Lipson SJ, Fossel AH, Katz JN. Measurement properties of a self-administered outcome measure in lumbar spinal stenosis. Spine (Phila Pa 1976) 1996;21:796-803.

67. Comer CM, Conaghan PG, Tennant A. Internal construct validity of the Swiss Spinal Stenosis questionnaire: Rasch analysis of a disease-specific outcome measure for lumbar spinal stenosis. Spine (Phila Pa 1976);36:1969-76.

68. Tuli SK, Yerby SA, Katz JN. Methodological approaches to developing criteria for improvement in lumbar spinal stenosis surgery. Spine (Phila Pa 1976) 2006;31:1276-80.

69. Steffen TM, Hacker TA, Mollinger L. Age- and gender-related test performance in community-dwelling elderly people: Six-Minute Walk Test, Berg Balance Scale, Timed Up \& Go Test, and gait speeds. Phys Ther 2002;82:128-37.

70. Guyatt GH, Sullivan MJ, Thompson PJ, et al. The 6-minute walk: a new measure of exercise capacity in patients with chronic heart failure. Can Med Assoc J 1985;132:919-23.

71. Briggs A, Clark T, Wolstenholme J, Clarke P. Missing... presumed at random: cost-analysis of incomplete data. Health Econ 2003;12:377-92. 
72. Donders AR, van der Heijden GJ, Stijnen T, Moons KG. Review: a gentle introduction to imputation of missing values. J Clin Epidemiol 2006;59:108791.

73. Sterne JA, White IR, Carlin JB, et al. Multiple imputation for missing data in epidemiological and clinical research: potential and pitfalls. BMJ 2009;338:b2393.

74. Svedmark P, Weidenhielm L, Nemeth G, et al. Model studies on segmental movement in lumbar spine using a semi-automated program for volume fusion. Comput Aided Surg 2008;13:14-22.

75. Svedmark P, Tullberg T, Noz ME, et al. Three-dimensional movements of the lumbar spine facet joints and segmental movements: in vivo examinations of normal subjects with a new non-invasive method. Eur Spine J;21:599-605.

76. Olivecrona H, Weidenhielm L, Olivecrona L, et al. Spatial component position in total hip arthroplasty. Accuracy and repeatability with a new CT method. Acta Radiol 2003;44:84-91.

77. Olivecrona H, Weidenhielm L, Olivecrona L, et al. A new CT method for measuring cup orientation after total hip arthroplasty: a study of 10 patients. Acta Orthop Scand 2004;75:252-60.

78. R Core Team, R: A Language and Environment for Statistical Computing. Vienna, Austria: R Foundation for Statistical Computing, 2014, Available at http://www.R-project.org.

79. Atlas SJ, Keller RB, Wu YA, Deyo RA, Singer DE. Long-term outcomes of surgical and nonsurgical management of lumbar spinal stenosis: 8 to 10 year results from the maine lumbar spine study. Spine (Phila Pa 1976) 2005;30:936-43.

80. Mahant PR, Stacy MA. Movement disorders and normal aging. Neurol Clin 2001;19:553-63, vi.

81. Kwok BC, Pua YH, Mamun K, Wong WP. The minimal clinically important difference of six-minute walk in Asian older adults. BMC Geriatr;13:23.

82. Slover J, Abdu WA, Hanscom B, Weinstein JN. The impact of comorbidities on the change in short-form 36 and oswestry scores following lumbar spine surgery. Spine (Phila Pa 1976) 2006;31:1974-80.

83. Battie MC, Videman T, Gill K, et al. 1991 Volvo Award in clinical sciences. Smoking and lumbar intervertebral disc degeneration: an MRI study of identical twins. Spine (Phila Pa 1976) 1991;16:1015-21.

84. Kauppila LI, Penttila A, Karhunen PJ, Lalu K, Hannikainen P. Lumbar disc degeneration and atherosclerosis of the abdominal aorta. Spine (Phila Pa 1976) 1994;19:923-9.

85. Kauppila LI, Tallroth K. Postmortem angiographic findings for arteries supplying the lumbar spine: their relationship to low-back symptoms. J Spinal Disord 1993;6:124-9.

86. Kelsey JL. An epidemiological study of acute herniated lumbar intervertebral discs. Rheumatol Rehabil 1975;14:144-59.

87. Hopper JL, Seeman E. The bone density of female twins discordant for tobacco use. N Engl J Med 1994;330:387-92.

88. Nguyen TV, Kelly PJ, Sambrook PN, Gilbert C, Pocock NA, Eisman JA. Lifestyle factors and bone density in the elderly: implications for osteoporosis prevention. J Bone Miner Res 1994;9:1339-46.

89. Law MR, Hackshaw AK. A meta-analysis of cigarette smoking, bone mineral density and risk of hip fracture: recognition of a major effect. BMJ 1997;315:841-6. 
90. Hawker GA. The epidemiology of osteoporosis. J Rheumatol Suppl 1996;45:2-5.

91. Yanbaeva DG, Dentener MA, Creutzberg EC, Wesseling G, Wouters EF. Systemic effects of smoking. Chest 2007;131:1557-66.

92. Watkins LR, Maier SF. The pain of being sick: implications of immune-tobrain communication for understanding pain. Annu Rev Psychol 2000;51:2957.

93. Triphati HL, Martin BR, Aceto MD. Nicotine-induced antinociception in rats and mice: correlation with nicotine brain levels. J pharmacol Exp Ther. 1982 Apr;221(1):91-6.

94. Fertig JB, Pomerleau OF, Sanders B. Nicotine-produced antinociception in minimally deprived smokers and ex-smokers. Addict Behav 1986;11:239-48.

95. Weingarten TN, Podduturu VR, Hooten WM, Thompson JM, Luedtke CA, Oh TH. Impact of tobacco use in patients presenting to a multidisciplinary outpatient treatment program for fibromyalgia. Clin J Pain 2009;25:39-43.

96. Behrend C, Schonbach E, Coombs A, Coyne E, Prasarn M, Rechtine G. Smoking Cessation Related to Improved Patient-Reported Pain Scores Following Spinal Care in Geriatric Patients. Geriatr Orthop Surg Rehabil;5:191-4.

97. Lehto MU, Honkanen P. Factors influencing the outcome of operative treatment for lumbar spinal stenosis. Acta Neurochir (Wien) 1995;137:25-8.

98. McGregor AH, Hughes SP. The evaluation of the surgical management of nerve root compression in patients with low back pain: Part 1: the assessment of outcome. Spine (Phila Pa 1976) 2002;27:1465-70.

99. Spratt KF, Keller TS, Szpalski M, Vandeputte K, Gunzburg R. A predictive model for outcome after conservative decompression surgery for lumbar spinal stenosis. Eur Spine J 2004;13:14-21.

100. Sinikallio S, Aalto T, Airaksinen O, et al. Lumbar spinal stenosis patients are satisfied with short-term results of surgery - younger age, symptom severity, disability and depression decrease satisfaction. Disabil Rehabil 2007;29:53744.

101. Lindstrom D, Sadr Azodi O, Wladis A, et al. Effects of a perioperative smoking cessation intervention on postoperative complications: a randomized trial. Ann Surg 2008;248:739-45.

102. Postacchini F, Cinotti G. Bone regrowth after surgical decompression for lumbar spinal stenosis. J Bone Joint Surg Br 1992;74:862-9.

103. Grob D, Humke T, Dvorak J. Degenerative lumbar spinal stenosis. Decompression with and without arthrodesis. J Bone Joint Surg Am 1995;77:103641.

104. Niggemeyer O, Strauss JM, Schulitz KP. Comparison of surgical procedures for degenerative lumbar spinal stenosis: a meta-analysis of the literature from 1975 to 1995. Eur Spine J 1997;6:423-9.

105. Rompe JD, Eysel P, Zollner J, Nafe B, Heine J. Degenerative lumbar spinal stenosis. Long-term results after undercutting decompression compared with decompressive laminectomy alone or with instrumented fusion. Neurosurg Rev 1999;22:102-6.

106. Katz JN, Lipson SJ, Lew RA, et al. Lumbar laminectomy alone or with instrumented or noninstrumented arthrodesis in degenerative lumbar spinal stenosis. Patient selection, costs, and surgical outcomes. Spine (Phila Pa 1976) 1997;22:1123-31.

107. Cornefjord M, Byrod G, Brisby H, Rydevik B. A long-term (4- to 12-year) follow-up study of surgical treatment of lumbar spinal stenosis. Eur Spine $\mathrm{J}$ 2000;9:563-70. 
108. Munting E, Roder C, Sobottke R, Dietrich D, Aghayev E. Patient outcomes after laminotomy, hemilaminectomy, laminectomy and laminectomy with instrumented fusion for spinal canal stenosis: a propensity score-based study from the Spine Tango registry. Eur Spine J;24:358-68.

109. Sigmundsson FG, Jonsson B, Stromqvist B. Preoperative pain pattern predicts surgical outcome more than type of surgery in patients with central spinal stenosis without concomitant spondylolisthesis: a register study of 9051 patients. Spine (Phila Pa 1976);39:E199-210.

110. Martin CR, Gruszczynski AT, Braunsfurth HA, Fallatah SM, O'Neil J, Wai EK. The surgical management of degenerative lumbar spondylolisthesis: a systematic review. Spine (Phila Pa 1976) 2007;32:1791-8.

111. Steiger F, Becker HJ, Standaert CJ, et al. Surgery in lumbar degenerative spondylolisthesis: indications, outcomes and complications. A systematic review. Eur Spine J;23:945-73.

112. Lombardi JS, Wiltse LL, Reynolds J, Widell EH, Spencer C, 3rd. Treatment of degenerative spondylolisthesis. Spine (Phila Pa 1976) 1985;10:821-7.

113. Mardjetko SM, Connolly PJ, Shott S. Degenerative lumbar spondylolisthesis. A meta-analysis of literature 1970-1993. Spine (Phila Pa 1976) 1994;19:2256S-65S.

114. Kleinstueck FS, Fekete TF, Mannion AF, et al. To fuse or not to fuse in lumbar degenerative spondylolisthesis: do baseline symptoms help provide the answer? Eur Spine J;21:268-75.

115. Sigmundsson FG, Jonsson B, Stromqvist B. Outcome of decompression with and without fusion in spinal stenosis with degenerative spondylolisthesis in relation to preoperative pain pattern: a register study of 1,624 patients. Spine $\mathrm{J} ; 15: 638-46$.

116. Rampersaud YR, Fisher C, Yee A, et al. Health-related quality of life following decompression compared to decompression and fusion for degenerative lumbar spondylolisthesis: a Canadian multicentre study. Can J Surg;57:E12633.

117. Pearson A, Blood E, Lurie J, et al. Degenerative spondylolisthesis versus spinal stenosis: does a slip matter? Comparison of baseline characteristics and outcomes (SPORT). Spine (Phila Pa 1976);35:298-305.

118. Ohrn A, Olai A, Rutberg H, Nilsen P, Tropp H. Adverse events in spine surgery in Sweden: a comparison of patient claims data and national quality register (Swespine) data. Acta Orthop;82:727-31.

119. Deyo RA, Hickam D, Duckart JP, Piedra M. Complications after surgery for lumbar stenosis in a veteran population. Spine (Phila Pa 1976);38:1695-702.

120. Jansson KA, Nemeth G, Granath F, Blomqvist P. Spinal stenosis re-operation rate in Sweden is $11 \%$ at 10 years--a national analysis of 9,664 operations. Eur Spine J 2005;14:659-63.

121. Mannion AF, Denzler R, Dvorak J, Grob D. Five-year outcome of surgical decompression of the lumbar spine without fusion. Eur Spine J;19:1883-91.

122. Hansraj KK, Cammisa FP, Jr., O'Leary PF, et al. Decompressive surgery for typical lumbar spinal stenosis. Clin Orthop Relat Res 2001:10-7.

123. Herno A, Airaksinen O, Saari T. Long-term results of surgical treatment of lumbar spinal stenosis. Spine (Phila Pa 1976) 1993;18:1471-4.

124. Katz JN, Lipson SJ, Chang LC, Levine SA, Fossel AH, Liang MH. Seven- to 10-year outcome of decompressive surgery for degenerative lumbar spinal stenosis. Spine (Phila Pa 1976) 1996;21:92-8. 
125. Tosteson AN, Lurie JD, Tosteson TD, et al. Surgical treatment of spinal stenosis with and without degenerative spondylolisthesis: cost-effectiveness after 2 years. Ann Intern Med 2008;149:845-53.

126. Harrop JS, Hilibrand A, Mihalovich KE, Dettori JR, Chapman J. Costeffectiveness of surgical treatment for degenerative spondylolisthesis and spinal stenosis. Spine (Phila Pa 1976);39:S75-85.

127. Tai CL, Hsieh PH, Chen WP, Chen LH, Chen WJ, Lai PL. Biomechanical comparison of lumbar spine instability between laminectomy and bilateral laminotomy for spinal stenosis syndrome - an experimental study in porcine model. BMC Musculoskelet Disord 2008;9:84.

128. Iguchi T, Kurihara A, Nakayama J, Sato K, Kurosaka M, Yamasaki K. Minimum 10-year outcome of decompressive laminectomy for degenerative lumbar spinal stenosis. Spine (Phila Pa 1976) 2000;25:1754-9.

129. Thome C, Zevgaridis D, Leheta O, et al. Outcome after less-invasive decompression of lumbar spinal stenosis: a randomized comparison of unilateral laminotomy, bilateral laminotomy, and laminectomy. J Neurosurg Spine 2005;3:129-41.

130. Nerland US, Jakola AS, Solheim O, et al. Minimally invasive decompression versus open laminectomy for central stenosis of the lumbar spine: pragmatic comparative effectiveness study. BMJ;350:h1603.

131. Overdevest GM, Jacobs W, Vleggeert-Lankamp C, Thome C, Gunzburg R, Peul W. Effectiveness of posterior decompression techniques compared with conventional laminectomy for lumbar stenosis. Cochrane Database Syst Rev;3:CD010036.

132. Shaffer WO, Spratt KF, Weinstein J, Lehmann TR, Goel V. 1990 Volvo Award in clinical sciences. The consistency and accuracy of roentgenograms for measuring sagittal translation in the lumbar vertebral motion segment. An experimental model. Spine (Phila Pa 1976) 1990;15:741-50.

133. Panjabi M, Chang D, Dvorak J. An analysis of errors in kinematic parameters associated with in vivo functional radiographs. Spine (Phila $\mathrm{Pa}$ 1976) 1992;17:200-5.

134. Axelsson P, Karlsson BS. Standardized provocation of lumbar spine mobility: three methods compared by radiostereometric analysis. Spine (Phila Pa 1976) 2005;30:792-7.

135. Johnsson R, Axelsson P, Stromqvist B. Posterolateral lumbar fusion using facet joint fixation with biodegradable rods: a pilot study. Eur Spine J 1997;6:144-8.

136. Solberg TK, Sorlie A, Sjaavik K, Nygaard OP, Ingebrigtsen T. Would loss to follow-up bias the outcome evaluation of patients operated for degenerative disorders of the lumbar spine? Acta Orthop;82:56-63.

137. Frobert O, Lagerqvist B, Olivecrona GK, et al. Thrombus aspiration during ST-segment elevation myocardial infarction. N Engl J Med;369:1587-97.

138. Frobin W, Brinckmann P, Leivseth G, Biggemann M, Reikeras O. Precision measurement of segmental motion from flexion-extension radiographs of the lumbar spine. Clin Biomech (Bristol, Avon) 1996;11:457-65.

139. Cabraja M, Mohamed E, Koeppen D, Kroppenstedt S. The analysis of segmental mobility with different lumbar radiographs in symptomatic patients with a spondylolisthesis. Eur Spine J;21:256-61. 



\section{Acta Universitatis Upsaliensis}

Digital Comprehensive Summaries of Uppsala Dissertations from the Faculty of Medicine 1135

Editor: The Dean of the Faculty of Medicine

A doctoral dissertation from the Faculty of Medicine, Uppsala University, is usually a summary of a number of papers. A few copies of the complete dissertation are kept at major Swedish research libraries, while the summary alone is distributed internationally through the series Digital Comprehensive Summaries of Uppsala Dissertations from the Faculty of Medicine. (Prior to January, 2005, the series was published under the title "Comprehensive Summaries of Uppsala Dissertations from the Faculty of Medicine".) 